\title{
Current Trends of High capacity Optical Interconnection Data Link in High Performance Optical Communication Systems
}

\author{
Dr. Ahmed Nabih Zaki Rashed \\ Electronics and Electrical Communications Engineering Department, \\ Faculty of Electronic Engineering, Menouf 32951, Menoufia University, Egypt \\ E-mail: ahmed_733@yahoo.com
}

\begin{abstract}
Optical technologies are ubiquitous in telecommunications networks and systems, providing multiple wavelength channels of transport at 2.5 $\mathrm{Gbit} / \mathrm{sec}$ to $40 \mathrm{Gbit} / \mathrm{sec}$ data rates over single fiber optic cables. Market pressures continue to drive the number of wavelength channels per fiber and the data rate per channel. This trend will continue for many years to come as electronic commerce grows and enterprises demand higher and reliable bandwidth over long distances. Electronic commerce, in turn, is driving the growth curves for single processor and multiprocessor performance in data base transaction and Web based servers. Ironically, the insatiable taste for enterprise network bandwidth, which has driven up the volume and pushed down the price of optical components for telecommunications, is simultaneously stressing computer system bandwidth increasing the need for new interconnection schemes and providing for the first time commercial opportunities for optical components in computer systems. The evolution of integrated circuit technology is causing system designs to move towards communication based architectures. We have presented the current tends of high performance system capacity of optical interconnection data transmission link in high performance optical communication and computing systems over wide range of the affecting parameters.
\end{abstract}

Index Terms - Optical Fiber Link, High Speed Optical Interconnection, Integrated Optics, Optical Source, Optical Detector

\section{Introduction}

Optical interconnections on silicon have been extensively investigated in recent years as interconnections become the bottleneck for the nextgeneration computing systems [1]. The goal of these investigations is to provide a compact, low power consumption, high bandwidth and low-latency optical interconnection system with full CMOS compatibility. Silicon based optical components such as low-loss silicon-on-insulator (SOI) optical waveguides [2], high speed silicon modulators, and Germanium on SOI detectors enabling large-scale optical integration on a silicon chip. While most attention is focused on single channel systems at this stage, wavelength division multiplexing (WDM) technology is necessary to fully utilize the ultra wide bandwidth of the optical interconnection medium, given that the transmission bandwidths of both silicon waveguides and optical fibers are on the order of 10 to $100 \mathrm{THz}$. As the key components of such a system, we show high speed and multi-channel modulation using cascaded silicon micro ring modulators [3].

Optical transparency is widely recognized to play a central role in next-generation optical networks and to offer significant networking advancements in terms of performance and cost [4]. The scalability of optical technology and the elimination of expensive opticalelectrical-optical (OEO) equipment is expected to significantly reduce the capital costs, whereas operational cost savings are expected to result from reduced power requirements and the flexibility of transparent service provisioning. The first steps toward this goal were point-to-point links routed via optical add-drop multiplexers (OADMs) at intermediate nodes, and increasingly the trend is toward so-called islands of transparency, with the eventual aim of fully meshed transparent optical networks with reconfigurable optical cross connects (OXCs) [5]. For the wavelength division multiplexing interconnection systems, in addition to the low power consumption and small size, ring modulators have another advantage: they modulate only light at particular wavelengths (the resonant wavelengths of the ring resonators) and allow light at all other wavelengths to pass through the modulators without been affected. Therefore, one can cascade several ring modulators with different resonant wavelengths on a single waveguide, and modulate different wavelengths of light independently [6].

In the present study, we have investigated the high capacity optical interconnection systems within actual operating bandwidth, signal to noise ratio at the receiver point, classical and Shannon transmission bit rates and products of both silica-doped and plastic 
materials based waveguides over wide range of the operating parameters.

\section{Simplified Architecture for WDM Optical Interconnection System}

As shown in Fig. 1 presents a simple architecture for a WDM interconnection system. A similar structure has been proposed for polymer modulators [7]. Light from a WDM source or a broadband source is sent into a silicon waveguide coupled to multiple ring modulators with different resonant wavelengths. If the input is a wavelength division multiplexing source, the resonant wavelength of each modulator needs to match the wavelength of each channel of the wavelength division multiplexing source. At the receiver side, these channels can be demultiplexed using similar ring resonators with drop ports, and detected separately. If the input is a broadband source, it only requires that the resonant wavelengths of the ring modulators match one-to-one with those of the ring demultiplexers $[8,9]$.

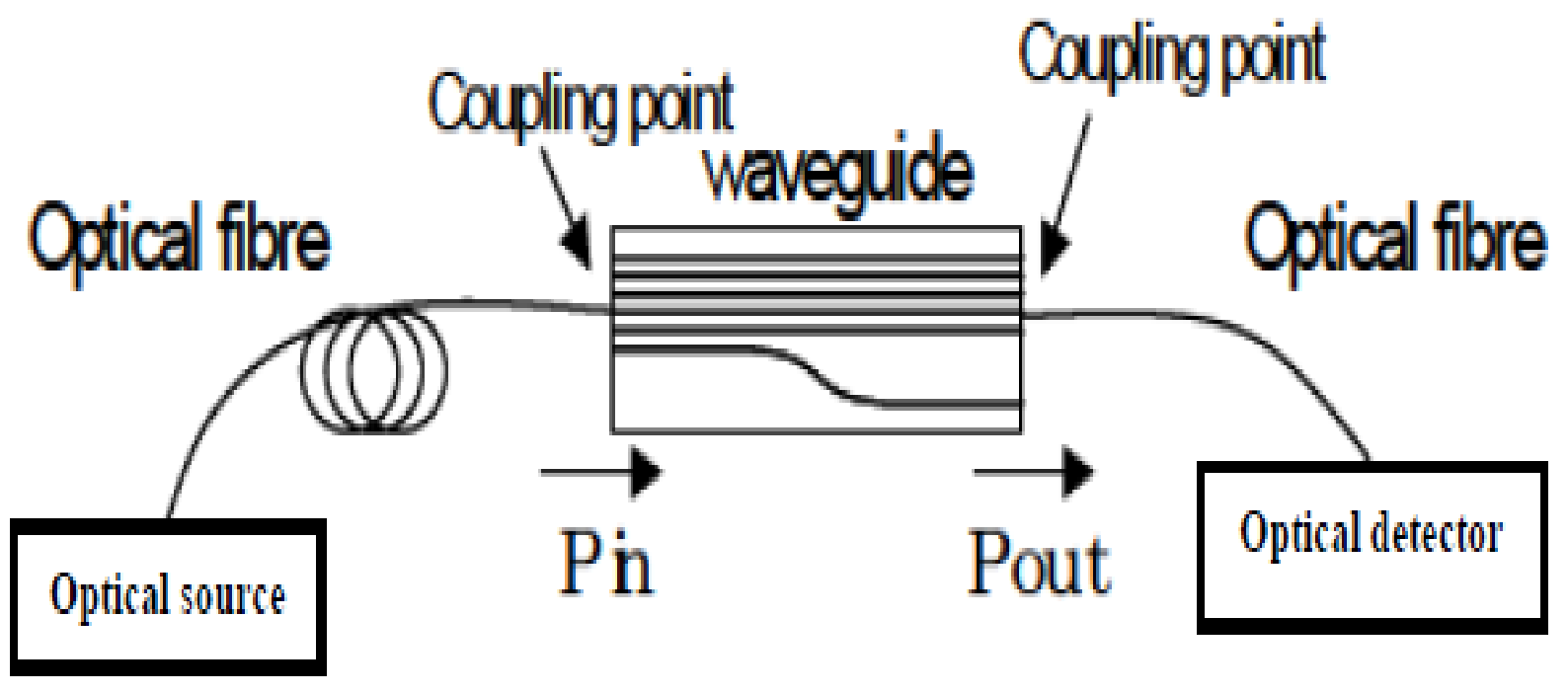

Fig. 1: WDM Optical interconnection system

\section{Theoretical Model Analysis}

In order to quantify the requirements for drive current for satisfactory laser modulation performance, the optical pulse data stream is fed into a thermal noise dominated simple photodiode receiver (50 $\Omega$ load) through $6 \mathrm{~dB}$ of optical loss (a typical number in short transmission distance optical interconnect). The received photocurrent after equalization at the receiver has the simple form [10].

$$
h(t)=\eta_{\text {link }} I_{m} \cos ^{2}\left(\frac{\pi B t}{2}\right),
$$

Where $I_{m}$ is the drive current to the laser, B is the transmission bit rate, the link efficiency $\left(\eta_{\text {link }}\right)$ includes the laser differential quantum efficiency ( $0.3 \mathrm{~W}$ att/A), the link loss $(6 \mathrm{~dB})$, and the detector responsivity $(0.5$ A/Watt). The required drive current to maintain a BER of $10^{-9}$ as a function of the laser threshold current. The bit error rate at the receiver can be:

$$
B E R=0.25\left(\left(\operatorname{erfc}\left(\frac{D}{\sigma \sqrt{2}}+\int_{0}^{t_{0}}\left(p\left(t_{\text {on }}\right) \operatorname{erfc}\left(\frac{h\left(t_{\text {on }}\right)-D}{\sigma \sqrt{2}}\right) d\left(t_{\text {on }}\right)\right)\right)\right)\right)
$$

Where $\mathrm{D}$ is the decision level, $\sigma$ is the variance of the thermal noise, and $\operatorname{erfc}(\mathrm{x})$ is the complementary error function. For each data point the decision level (D) is numerically chosen to minimize the corresponding BER. Where the distribution function of turn on time of the laser $\left(\mathrm{t}_{\mathrm{on}}\right)$ can be expressed as:

$$
p\left(t_{\text {on }}\right)=\frac{\eta}{t_{\text {on }}}\left(1-\frac{t_{\text {on }}}{t_{0}}\right)^{-\eta}
$$

This required drive current is used to calculate the average electrical power consumption for the laser given by the following formulas:

$$
P_{E}=0.5 I_{m}\left(V_{0}+I_{m} Z_{0}\right)
$$

The initial carrier number in the laser $\mathrm{n}$ depends on the number of " 0 " bits which precede the " 1 " bit. At the end of a bit, the carrier number decays exponentially with time constant $\tau$ such that:

$$
n_{i}=n_{t h} \exp \left(\frac{-N T}{\tau}\right),
$$

Where $\mathrm{N}$ is the number of " 0 " bits preceding the considered transmission bit, $\mathrm{n}_{\text {th }}$ is the threshold carrier number, $\tau$ is the carrier life time and $T=1 / B$. The threshold current and turn on time of the laser can be expressed by [11]: 


$$
\begin{gathered}
I_{t h}=\frac{n_{t h} e}{\tau}, \\
t_{\text {on }}=t_{0}\left(1-\exp \left(\frac{-N T}{\tau}\right)\right),
\end{gathered}
$$

Where e is the electronic charge, ${ }^{t_{0}}=\tau I_{t h} / I_{m}$, and the coupling efficiency from optical source to the optical link is:

$$
\eta_{\text {link }}=\ln (2) B \tau
$$

\subsection{Materials based connector}

A connector is used to join a fiber cable to a transmitter or receiver, or is used to join together strands of fiber link. A connector for fiber is similar in concept to a traditional electrical connector, but the fiber connector is actually more delicate, as it must precisely align the internal fibers to insure a proper flow of data through the cables. For single mode fibers (SMF), the Fresnel reflection loss caused by the differences between the refractive indeces of the silica doped and plastic fibers and the material separation are given as the following [13]:

$$
L_{C}=20 \log \left(\frac{4 n n_{\text {clad }}}{\left(n+n_{\text {clad }}\right)^{2}}\right), \quad, \mathrm{dB} / \mathrm{cm}
$$

Where $\mathrm{n}$ is the refractive-index of silica-doped or plastic materials. The cladding refractive index can be expressed as a function of both silica-doped and plastic core refractive indices and relative refractive-index difference as the following:

$$
n_{\text {clad }}=(1-\Delta n) n
$$

Then by substituting from Eq. (10) into Eqs. (9), we can obtain:

$$
L_{C}=20 \log \left(\frac{4(1-\Delta n) n^{2}}{(2 n-\Delta n \cdot n)^{2}}\right),_{\mathrm{dB} / \mathrm{cm}}
$$

The relative refractive-index difference $\Delta \mathrm{n}$ for both silica-doped and plastic materials are given by:

$$
\Delta n=\frac{n-n_{\text {clad }}}{n}
$$

The refractive-index of silica-doped material waveguide based on Sellemier equation is given by [14]:

$$
n^{2}=1+\frac{A_{1} \lambda^{2}}{\lambda^{2}-A_{2}^{2}}+\frac{A_{3} \lambda^{2}}{\lambda^{2}-A_{4}^{2}}+\frac{A_{5} \lambda^{2}}{\lambda^{2}-A_{6}^{2}}
$$

The Sellmeier coefficients of the refractive index of this waveguide are cast as [14]:

$$
\begin{array}{ccccc}
\mathrm{A}_{1}= & 0.691663+0.1107001 * & \mathrm{x}, & \mathrm{A}_{2}= \\
\left(0.0684043+0.000568306 * \mathrm{x}^{2}\right. & * & \left(\mathrm{~T} / \mathrm{T}_{0}\right)^{2}, & \mathrm{~A}_{3}= \\
0.4079426+0.31021588 * \mathrm{x}, & & & \\
\mathrm{A}_{4}=(0.1162414+0.03772465 * \mathrm{x})^{2} * & \left(\mathrm{~T} / \mathrm{T}_{0}\right)^{2}, & \mathrm{~A}_{5}=
\end{array}
$$
$0.8974749-0.043311091 \quad * \quad \mathrm{x}$, and $\mathrm{A}_{6}=$ $(9.896161+1.94577 * \mathrm{x})^{2}$. Where $\mathrm{T}$ is the ambient temperature in ${ }^{\circ} \mathrm{C}, \mathrm{T}_{0}$ is considered to be as $25{ }^{\circ} \mathrm{C}$ (room temperature), and $\mathrm{x}$ is the ratio of germania dopant added to silica material to improve its optical performance characteristics within the range of $0.0 \leq \mathrm{x}$ $\leq 0.3[14]$. Also the plastic cable core material which the investigation of the spectral variations of the waveguide refractive-index (n) requires Sellemeier equation under the form [15]:

$$
n^{2}=1+\frac{B_{1} \lambda^{2}}{\lambda^{2}-B_{2}^{2}}+\frac{B_{3} \lambda^{2}}{\lambda^{2}-B_{4}^{2}}+\frac{B_{5} \lambda^{2}}{\lambda^{2}-B_{6}^{2}}
$$

For the plastic material, the coefficients of the Sellmeier equation and refractive-index variation with ambient temperature are as: $\mathrm{B}_{1}=0.4963, \mathrm{~B}_{2}=0.6965$ $\left(\mathrm{T} / \mathrm{T}_{0}\right), \mathrm{B}_{3}=0.3223, \mathrm{~B}_{4}=0.718\left(\mathrm{~T} / \mathrm{T}_{0}\right), \mathrm{B}_{5}=0.1174$, and $\mathrm{B}_{6}=9.237\left(\mathrm{~T} / \mathrm{T}_{0}\right)$.

\subsection{Materials based optical waveguide}

Special emphasis is given to the transmission characteristics of silica-doped and plastic fibers as promise links in long and short distance optical communications. Silica-doped and plastic waveguide characteristics (spectral loss and chromatic dispersion) are thermal dependent, thus, these two variables must be taken into account when studying the transmission bit rate capacity of the waveguides over wide range of the operating parameters.

\subsubsection{Silica-doped material based waveguide}

Based on the models of [14], the spectral losses of silica-doped waveguides are cast as:

$$
\alpha=\alpha_{I}+\alpha_{S}+\alpha_{U V}+\alpha_{I R}, \mathrm{~dB} / \mathrm{cm}
$$

Where $\quad \alpha_{I} \equiv$ the intrinsicloss $\cong 3 \times 10^{-8}, \quad \mathrm{~dB} / \mathrm{cm}$, and(16)

$\alpha_{S} \equiv$ Rayleighscattering $=\left(\frac{0.75+66 \Delta n}{\lambda^{4} \times 10^{-5}}\right)\left(\frac{T}{T_{0}}\right)$,

Where the scattering loss is linearity is related to the ambient temperature $\mathrm{T}, \mathrm{T}_{0}$ is a reference temperature or room temperature and is taken as value of $25^{\circ} \mathrm{C}, \Delta \mathrm{n}$ and $\lambda$ are the relative refractive index difference and operating optical signal wavelength respectively. The absorption losses $\alpha_{\mathrm{UV}}$ and $\alpha_{\mathrm{IR}}$ are given as [14]:

$$
\alpha_{U V}=1.1 \times 10^{-9} \omega_{g e} \% e^{4.9 \lambda}, \mathrm{dB} / \mathrm{cm}
$$




$$
\alpha_{I R}=\left(7 \times 10^{-10} e^{-24 / \lambda}\right)^{2}, \quad \mathrm{~dB} / \mathrm{cm}
$$

Where $\omega_{\mathrm{ge}} \%$ is the weight percentage of germania, $\mathrm{GeO}_{2}$ added to optical silica fibers to improve its optical transmission characteristics. The percentage of germania $\omega_{\mathrm{ge}} \%$ and the mole fraction $\mathrm{x}$ are cast under the form:

$$
\omega_{g e} \%=213.27 x-594 x^{2}+2400 x^{3}-4695 x^{4}
$$

The first and second differentiation of Eq. (13) with respect to operating signal wavelength $\lambda$ which yields:

$$
\begin{aligned}
& \frac{d n}{d \lambda}=-\left(\frac{\lambda}{n}\right) \cdot\left(\frac{A_{1} A_{2}^{2}}{\left(\lambda^{2}-A_{2}^{2}\right)^{2}}+\frac{A_{3} A_{4}^{2}}{\left(\lambda^{2}-A_{4}^{2}\right)^{2}}+\frac{A_{5} A_{6}^{2}}{\left(\lambda^{2}-A_{6}^{2}\right)^{2}}\right), \\
& \frac{d^{2} n}{d \lambda^{2}}=-\left(\frac{1}{n}\right) \cdot\left(\frac{A_{1} A_{2}^{2}\left(3 \lambda^{2}+A_{2}^{2}\right)}{\left(\lambda^{2}-A_{2}^{2}\right)^{3}}+\frac{A_{3} A_{4}^{2}\left(3 \lambda^{2}+A_{4}^{2}\right)}{\left(\lambda^{2}-A_{4}^{2}\right)^{3}}+\frac{A_{5} A_{6}^{2}\left(3 \lambda^{2}+A_{6}^{2}\right)}{\left(\lambda^{2}-A_{6}^{2}\right)^{3}}\right)-\left(\frac{d n}{d \lambda}\right)^{2},
\end{aligned}
$$

\subsubsection{Plastic material based waveguide}

Plastics, as all any organic materials, absorb light in the ultraviolet spectrum region. The mechanism for the absorption depends on the electronic transitions between energy levels in molecular bonds of the material. Generally the electronic transition absorption peaks appear at wavelengths in the ultraviolet region, and their absorption tails have an influence on the plastic optical fiber (POF) transmission loss [15]. According to urbach's rule, the attenuation coefficient $\alpha_{\mathrm{e}}$ due to electronic transitions in POF is given by [15]:

$$
\alpha_{e}\left(\text { plastid }=1.10 \times 10^{-10} \exp \left(\frac{8}{\lambda}\right), \quad \mathrm{dB} / \mathrm{cm}\right.
$$

Where $\lambda$ is the optical signal wavelength of light in $\mu \mathrm{m}$ and . In addition, there is another type of intrinsic loss, caused by fluctuations in the density, and composition of the material, which is known as Rayleigh scattering.. This phenomenon gives the rise to scattering coefficient $\alpha_{R}$ that is inversely proportional to the fourth power of the wavelength, i.e., the shorter is $\lambda$ the higher the losses are. For POF, it is shown that $\alpha_{R}$ is given by [15].

$$
\alpha_{R}(\text { plasti })=13 \times 10^{-5}\left(\frac{0.633}{\lambda}\right)^{4}, \quad \mathrm{~dB} / \mathrm{cm}
$$

Then the total losses of plastic optical fibers are given by:

$$
\alpha(\text { plasti })=\alpha_{e}(\text { plastid })+\alpha_{R}(\text { plasti }) \mathrm{dB} / \mathrm{cm}
$$

The first and second differentiation of Eq. (14) with respect to operating wavelength $\lambda$ which yields:

$$
\begin{aligned}
& \frac{d n}{d \lambda}=-\left(\frac{\lambda}{n}\right) \cdot\left(\frac{B_{1} B_{2}^{2}}{\left(\lambda^{2}-B_{2}^{2}\right)^{2}}+\frac{B_{3} B_{4}^{2}}{\left(\lambda^{2}-B_{4}^{2}\right)^{2}}+\frac{B_{5} B_{6}^{2}}{\left(\lambda^{2}-B_{6}^{2}\right)^{2}}\right), \\
& \frac{d^{2} n}{d \lambda^{2}}=-\left(\frac{1}{n}\right) \cdot\left(\frac{B_{1} B_{2}^{2}\left(3 \lambda^{2}+B_{2}^{2}\right)}{\left(\lambda^{2}-B_{2}^{2}\right)^{3}}+\frac{B_{3} B_{4}^{2}\left(3 \lambda^{2}+B_{4}^{2}\right)}{\left(\lambda^{2}-B_{4}^{2}\right)^{3}}+\frac{B_{5} B_{6}^{2}\left(3 \lambda^{2}+B_{6}^{2}\right)}{\left(\lambda^{2}-B_{6}^{2}\right)^{3}}\right)-\left(\frac{d n}{d \lambda}\right)^{2},
\end{aligned}
$$

\subsection{Classical transmission bit rate}

The total pulse broadening due to material and waveguide dispersion in single mode fibers is given by:

$$
\Delta \tau=10^{-5} \cdot D_{t} \cdot \Delta \lambda \cdot L_{w} \quad \text { nsec } / \mathrm{nm} . \mathrm{cm}
$$

Therefore, the total chromatic dispersion in standard single mode fiber that limits the transmission bit rates in system based optical communication can be calculated as follows [16]:

$$
D_{t}=-\left(M_{m d}+M_{w d}\right),
$$

Where $M_{m d}$ is the material dispersion coefficient in nsec/nm.cm, $\mathbf{M}_{\mathrm{wd}}$ is the waveguide dispersion coefficient in nsec/nm.cm, $\Delta \lambda$ is the spectral line width of the used optical source in $\mathrm{nm}$, and $\mathrm{L}_{\mathrm{w}}$ is the waveguide length in $\mathrm{cm}$. The material dispersion coefficient is given as the following equation:

$$
M_{m d}=-\frac{\lambda}{c} \frac{d^{2} n}{d \lambda^{2}}-\frac{\Delta \lambda}{2 c}\left(\frac{d^{2} n}{d \lambda^{2}}\right),
$$

The waveguide dispersion coefficient is given by the following expression:

$$
M_{w d}=-n_{\text {clad }}\left(\frac{\Delta n}{c \lambda_{s}}\right) F(V)
$$

Where $\mathrm{n}_{\text {clad }}$ is the refractive-index of the cladding material, $\Delta \mathrm{n}$ is the relative refractive-index difference, $\lambda$ is the operating optical signal wavelength in $\mu \mathrm{m}$, and $\mathrm{F}(\mathrm{V})$ is a function of $\mathrm{V}$ number or normalized frequency. Based on the work [16], they designed the function $F(V)$ is a function of $V$ as the following expression:

$$
F(V)=1.38 V-6.98 V^{2}+13.45 V^{3}-4.84 V^{4}-1.48 V^{5},
$$

When they are employing V-number in the range of $(0 \leq \mathrm{V} \leq 1.15)$ yields the above expression. We are taking into account $\mathrm{V}$-number as unity to emphasis single mode operation. Then the classical transmission bit rate as a function of waveguide length, total losses $(\alpha)$, and total pulse broadening $(\Delta \tau)$ due to total chromatic dispersion is given by [16]: 


$$
B(\text { Transmissínbitrate })=\frac{5000 e^{-\alpha L_{w}}}{5+\Delta \tau \cdot L_{w}}, \mathrm{Gbit} / \mathrm{sec}
$$

Then the transmission bit rate length product can be expressed as the following expression:

$$
P_{W}=B . L_{w}, \text { Gbit.cm } / \mathrm{sec}
$$

\subsection{Shannon transmission capacity}

The signal to noise ratio (SNR) is a measure of signal quality at the receiver side, it is given by [16]:

$$
\begin{aligned}
& S N R=\frac{\left(G P_{0} \rho\right)^{2} Z_{0}}{4 k T B . W_{\text {sig. }}+2 e Z_{0} B \cdot W_{\text {sig. }} G^{n}\left(I_{D}+\rho P_{0}\right)}, \\
& (S N R)_{d B}=10 \log S N R,
\end{aligned}
$$

Where $\mathrm{P}_{0}$ is the received or output optical power, $\rho$ is the detector's unamplified responsivity, $G$ is the detector gain if an avalanche photodiode (APD) is used, $n$ accounts for the excess noise of the avalanche photodiode (usually between the value of 2 and 3), B. $W_{\text {sig. }}$ is the signal bandwidth at the receiver, $\mathrm{k}$ is Boltzmann's constant $\left(\mathrm{k}=1.38 \times 10^{-23} \mathrm{~J} / \mathrm{K}\right)$, e is the magnitude of the charge on an electron $\left(1.6 \times 10^{-19}\right.$ coulomb), $\mathrm{T}$ is the ambient temperature in ${ }^{\circ} \mathrm{C}, \mathrm{I}_{\mathrm{D}}$ is the detector's dark current, and $\mathrm{Z}_{0}$ is the resistance of the load resistor that follows the photodetector. The signal bandwidth and maximum transmission bit rate or capacity according to modified Shannon technique is given by [17]:

$$
\begin{aligned}
B . W_{\text {sig. }} & =\frac{0.44}{\Delta \tau \cdot L_{w}}, \mathrm{GHz} \\
B_{R(S H)} & =B \cdot W_{\text {sig. }} \log _{2}(1+S N R)
\end{aligned}
$$

Where B.W $W_{\text {sig. }}$ is the actual bandwidth of the optical signal and SNR is the signal to noise ratio in absolute value (i. e., not in $\mathrm{dB}$ ). Where the Shannon bandwidthlength product within waveguide can be given by [18, 19]:

$$
P_{S H}=B_{R}(S H) \cdot L_{w}, \text { Gbit.cm } / \mathrm{sec}
$$

Where $L_{w}$ is the waveguide length, and $B_{R}(\mathrm{SH})$ is the Shannon transmission bit rate.

\section{Simulation Results and Discussions}

We have analyzed parametrically, and numerically the high transmission bit rate and product of high

\begin{tabular}{|c|c|c|}
\hline $\begin{array}{l}\text { Operating } \\
\text { parameter }\end{array}$ & Definition & $\begin{array}{l}\text { Value and } \\
\text { units }\end{array}$ \\
\hline $\mathrm{T}$ & Ambient temperature & $\begin{array}{l}25{ }^{\circ} \mathrm{C} \leq \mathrm{T} \leq \\
45^{\circ} \mathrm{C}\end{array}$ \\
\hline $\mathrm{L}_{\mathrm{W}}$ & Waveguide length & $\begin{array}{l}2 \mathrm{~cm} \leq \mathrm{L}_{\mathrm{m}} \leq \\
5 \mathrm{~cm}\end{array}$ \\
\hline $\mathrm{P}_{0}$ & Output power & $\begin{array}{l}0.2 \text { Watt } \leq \\
\mathrm{P}_{0} \leq 0.597 \\
\text { Watt }\end{array}$ \\
\hline $\mathrm{T}_{0}$ & Room temperature & $25^{\circ} \mathrm{C}$ \\
\hline$\lambda$ & $\begin{array}{l}\text { signal operating } \\
\text { wavelength }\end{array}$ & $\begin{array}{l}1.3 \mu \mathrm{m} \leq \lambda \\
\leq 1.65 \mu \mathrm{m}\end{array}$ \\
\hline $\mathrm{Z}_{0}$ & Series and load resist ance & $100 \Omega$ \\
\hline G & Detector gain & $\begin{array}{l}20 \mathrm{~dB} \leq \mathrm{G} \leq \\
50 \mathrm{~dB}\end{array}$ \\
\hline $\mathrm{I}_{\mathrm{D}}$ & Detect or dark current & $8 \mathrm{nA}$ \\
\hline$\rho$ & detector responsivity & $\begin{array}{l}0.25 \text { A/Watt } \\
\leq \mathrm{G} \leq 0.8 \\
\text { A/Watt }\end{array}$ \\
\hline$\Delta \lambda$ & $\begin{array}{l}\text { Spectral line width of } \\
\text { optical source }\end{array}$ & $0.1 \mathrm{~nm}$ \\
\hline $\mathrm{V}_{0}$ & Turn on voltage & $\begin{array}{l}1 \text { Volt } \leq V_{0} \\
\leq 10 \text { Volt }\end{array}$ \\
\hline$\Delta \mathrm{n}_{\text {silica-doped }}$ & $\begin{array}{l}\text { Refractive index } \\
\text { difference of silica-doped }\end{array}$ & $\begin{array}{l}0.005 \leq \Delta \mathrm{n} \\
\leq 0.009\end{array}$ \\
\hline$\Delta \mathrm{n}_{\text {plastic }}$ & $\begin{array}{l}\text { Refractive index } \\
\text { difference of plastic }\end{array}$ & $\begin{array}{l}0.05 \leq \Delta \mathrm{n} \leq \\
0.09\end{array}$ \\
\hline $\mathrm{n}_{\text {silica-doped }}$ & $\begin{array}{l}\text { Refractive index of silica- } \\
\text { doped }\end{array}$ & $\begin{array}{l}1.442 \leq \mathrm{n} \leq \\
1.448\end{array}$ \\
\hline $\mathrm{n}_{\text {plastic }}$ & Refractive index of plastic & $\begin{array}{l}1.494 \leq \mathrm{n} \leq \\
1.554\end{array}$ \\
\hline$t_{o n}$ & Turn on time of the laser & $\begin{array}{l}1 \mathrm{msec} \leq \mathrm{t}_{\mathrm{on}} \\
\leq 10 \mathrm{msec}\end{array}$ \\
\hline$\tau$ & Carrier life time & $\begin{array}{l}2 \mathrm{nsec} \leq \tau \leq \\
10 \mathrm{nsec}\end{array}$ \\
\hline B & Transmission bit rate & $\begin{array}{l}1 \mathrm{Gbit} / \mathrm{sec} \leq \\
\mathrm{B} \leq 10 \\
\mathrm{Gbit} / \mathrm{sec}\end{array}$ \\
\hline $\mathrm{I}_{\mathrm{th}}$ & Threshold current & $\begin{array}{l}1 \mu \mathrm{A} \leq \mathrm{I}_{\mathrm{th}} \leq \\
50 \mu \mathrm{A}\end{array}$ \\
\hline $\mathrm{I}_{\mathrm{m}}$ & Drive current of the laser & $\begin{array}{l}0.1 \mathrm{~mA} \leq \mathrm{I}_{\mathrm{m}} \\
\leq 0.5 \mathrm{~mA}\end{array}$ \\
\hline$\eta_{\text {Link }}$ & Link efficiency & $\begin{array}{l}60 \% \leq \eta \leq \\
95 \%\end{array}$ \\
\hline c & Speed of light & $3 \times 10^{8} \mathrm{~m} / \mathrm{sec}$ \\
\hline
\end{tabular}
capacity optical interconnection systems in modern communication and computing systems. Based on the modeling equations analysis and the assumed set of the operating parameters as shown in Table 1.
Table 1: Proposed operating parameters for optical interconnection model 
The following facts are assured as shown in the series of Figs. (2-27):

i) Fig. 2. has assured that as that as drive current of the laser increases, the bit error rate decreases at constant threshold current. Moreover as threshold current increases, the bit error rate also increases at constant drive current of the laser.

ii) As shown in Figs. (3, 4) have demonstrated that as both drive current and turn on voltage of the laser increases, the electrical power also increases. As well as transmission bit rate increases, the electrical power also increases.

iii) Figs. $(5,6)$ have proved that carrier life time in the laser diode increases, both turn on time of the laser and coupling efficiency also increases at constant transmission bit rate. With increasing transmission bit rates, the turn on time of the laser and coupling efficiency to the waveguide must be increased.

iv) Fig. 7 has indicated that as carrier life time in the laser diode increases, the threshold current decreases at constant drive current to the laser. But as drive current to the laser increases, the threshold current must be increased.

v) Fig. 8 has demonstrated that as both coupling efficiency of the laser to the optical link, and turn on time of the laser increases, the transmission bit rates also increase.

vi) As shown in Figs. (9, 10) have demonstrated that as both refractive index of silica-doped and plastic materials based waveguide, and relative refractive index difference increase, the coupling losses also increase. But we find the higher coupling loss for plastic material based waveguide.

vii) As shown in Figs. $(11,12)$ have proved that as ambient temperature percentage amount of germanium and relative refractive index difference increase, the total losses of silicadoped material based waveguide also increase. But as operating signal wavelength increase, the total loss of silica-doped material based waveguide decreases.

viii) Fig. (13) has assured that as operating signal wavelength increase, the total loss of plastic material based waveguide decreases.

ix) Figs. (14, 15) have assured that as both waveguide length and relative refractive index difference decrease, the classical transmission bit rate increases for both silica-doped and plastic materials based waveguide. We observed the increased classical transmission bit rate for silica-doped waveguide than plastic waveguide.

x) Figs. (16-18) have demonstrated that as waveguide length increases and ambient temperature decrease, the transmission bit rate-length product increases for both silicadoped and plastic materials based waveguide. We observed the increased classical bit ratelength product for silica-doped waveguide than plastic waveguide. Moreover as percentage amount of germanium increases, this leads to the increased bit rate length product within silica-doped material based waveguide.

xi) As shown in Figs. $(19,20)$ have indicated that as relative refractive index difference decreases, and operating signal wavelength increases, the classical transmission bit rate increases for both silica-doped and plastic materials based waveguide. As well as we have observed the increased classical transmission bit rate for silica-doped material based waveguide than plastic material based waveguide.

xii) Figs. (21, 22) have assured that as both ambient temperature and relative refractive index difference decrease, the signal bandwidth increases for both silica-doped and plastic materials based waveguide. We observed the increased signal bandwidth for silica-doped material waveguide than plastic material based waveguide.

xiii) As shown in Fig. (23) has indicated that as ambient temperature decreases and output power at the receiver point increase, the signal to noise ratio also increases for both silicadoped and plastic materials based waveguide.

xiv) Figs. (24-27) have assured that as signal to noise ratio increases and waveguide length decreases, the Shannon transmission bit rate increases for both silica-doped and plastic materials based waveguide. Moreover as both signal to noise ratio and waveguide length increase, this leads to increase of Shannon product for both silica-doped and plastic materials based waveguide. 


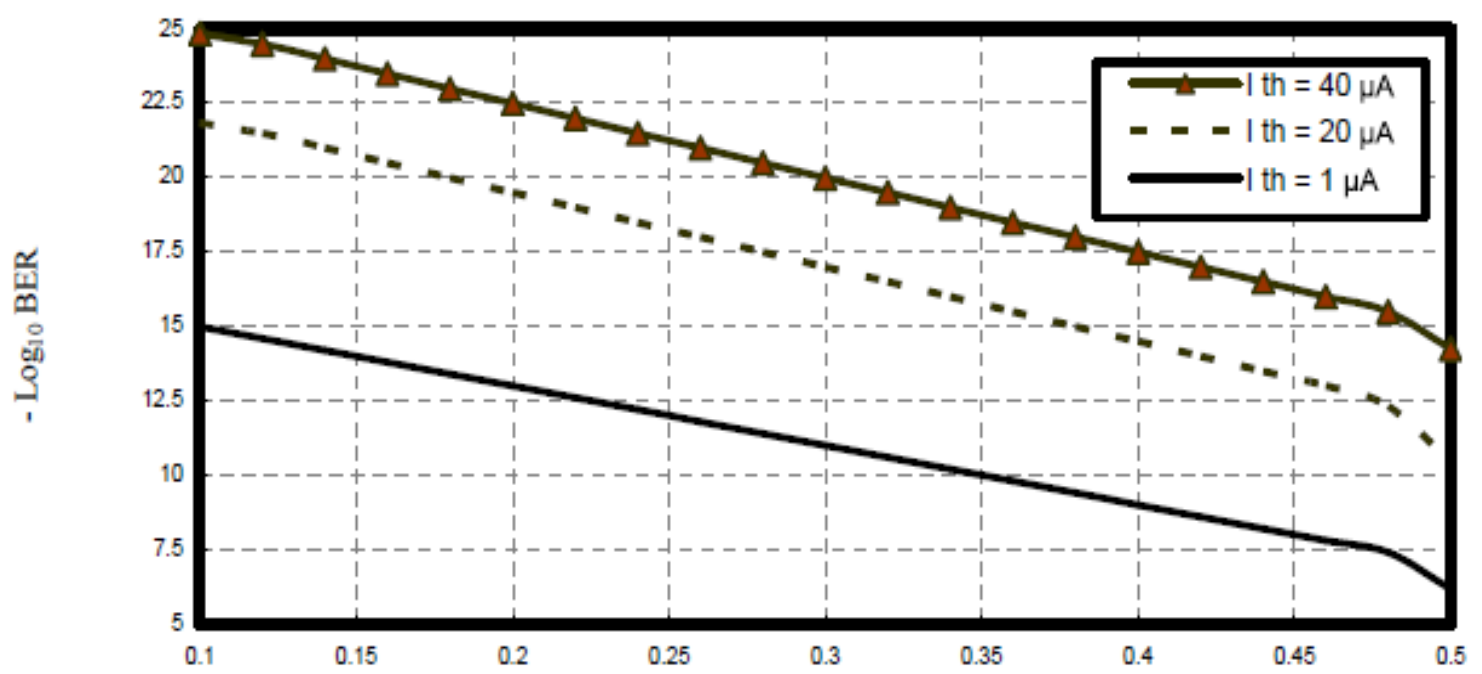

Drive current of the laser, $I_{m}, \mathrm{~mA}$

Fig. 2. Variations of bit error rate (BER) against drive current of the laser at the assumed set of parameters.

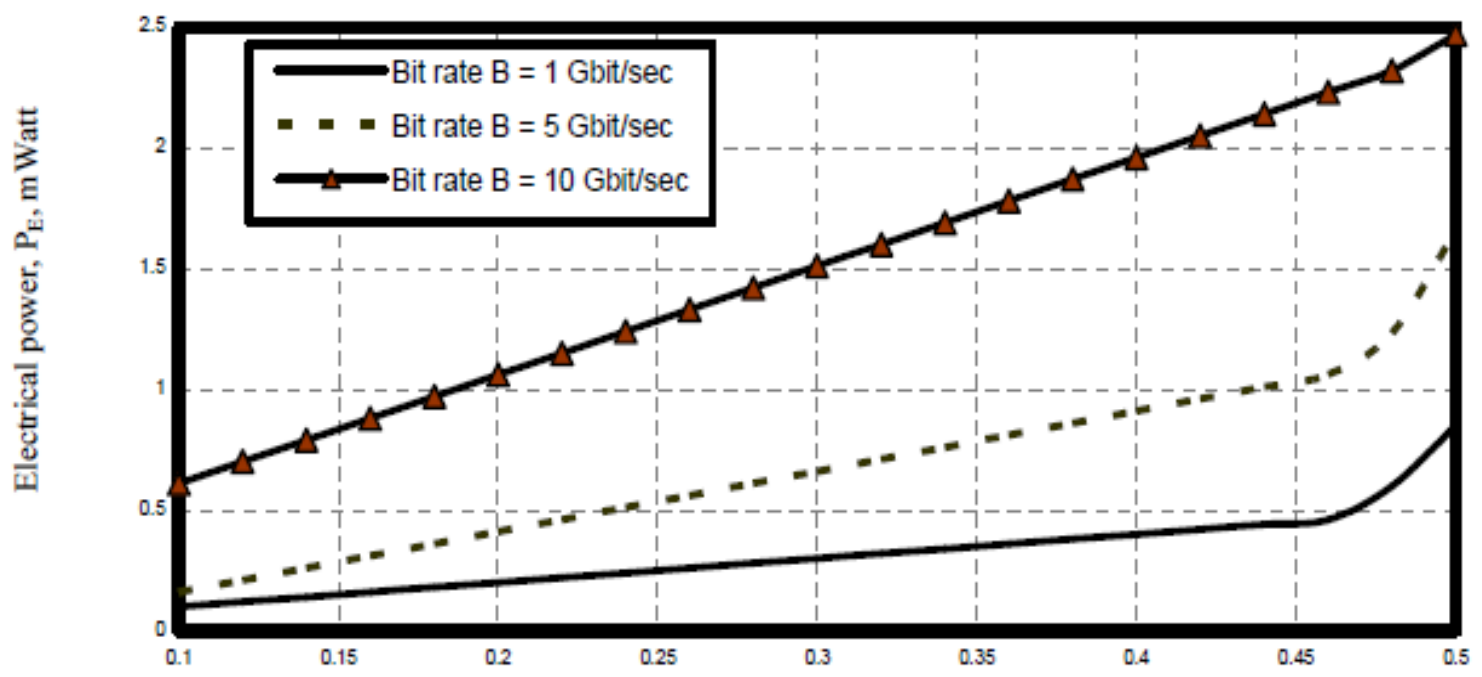

Drive current to the laser, $\mathrm{I}_{\mathrm{m}}, \mathrm{mA}$

Fig. 3. Variations of electrical power against drive current of the laser at the assumed set of parameters.

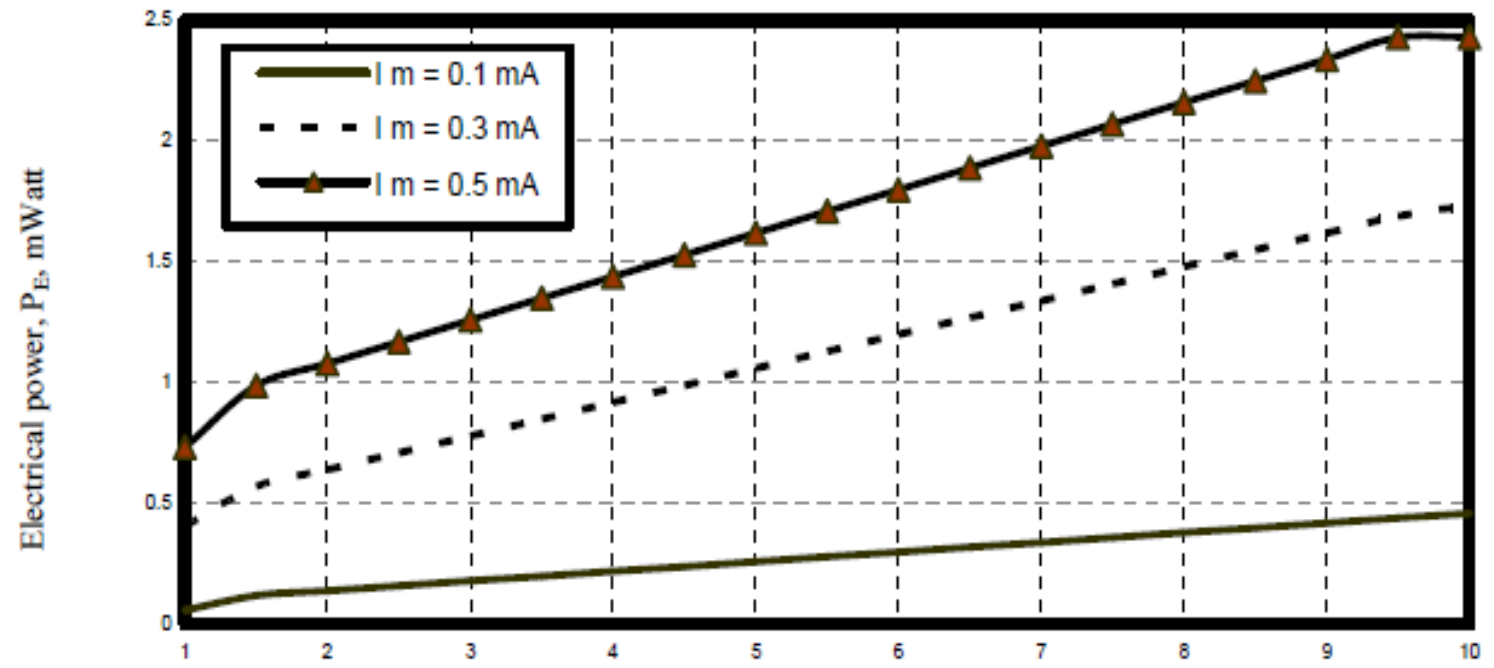

Turn on voltage of the laser, $\mathrm{V}_{0}$, Volt

Fig. 4. Variations of electrical power against turn on voltage of the laser at the assumed set of parameters. 


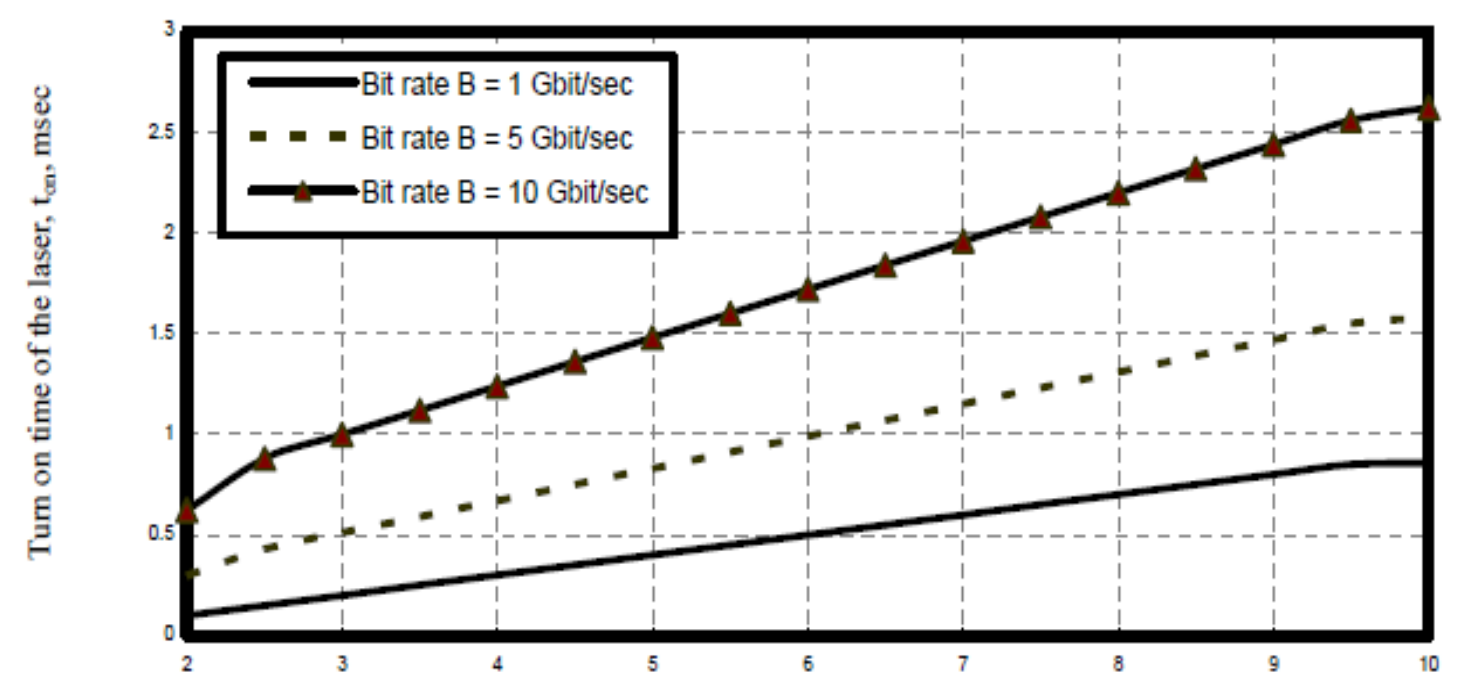

Carrier life time in the laser diode, $\tau$, nsec

Fig. 5. Variations of turn on time of the laser against carrier life time in the laser at the assumed set of parameters.

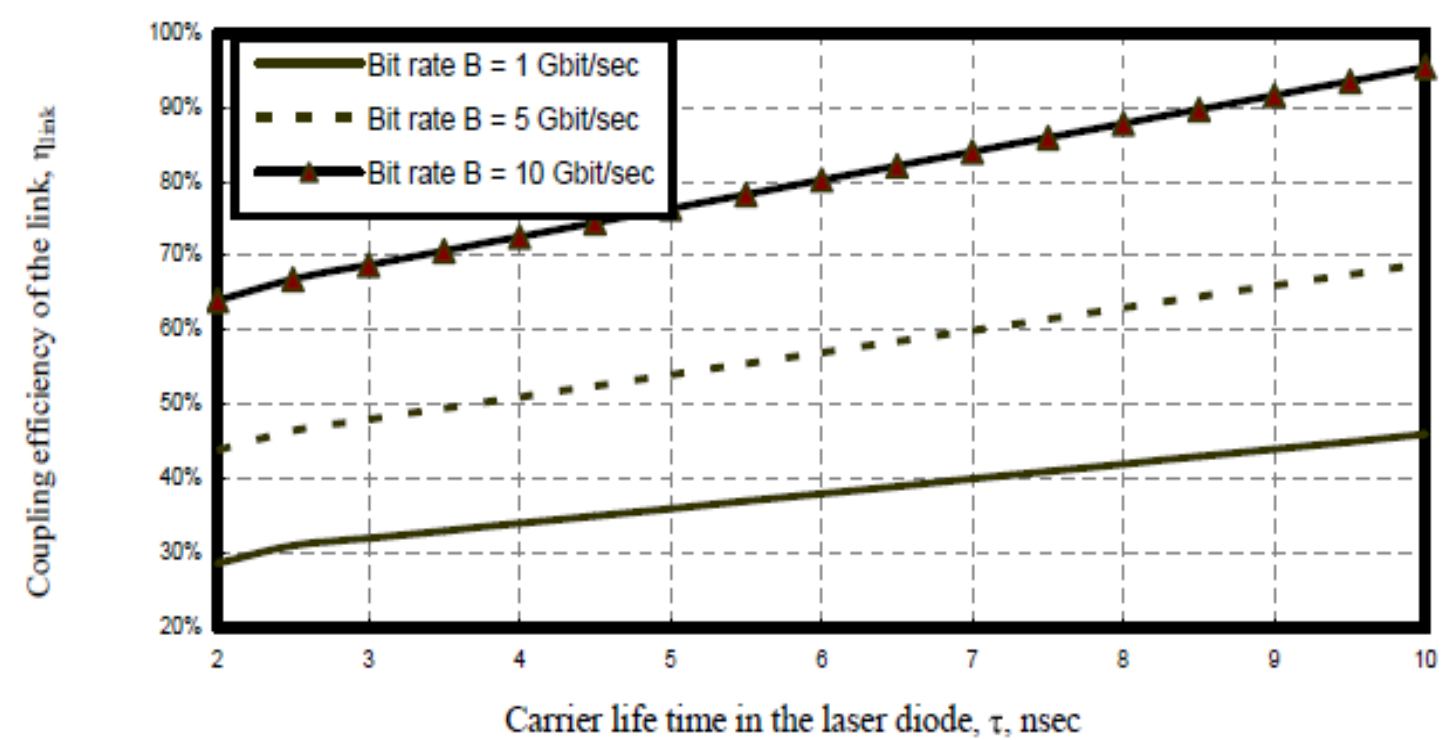

Fig. 6. Variations of turn on time of the laser against carrier life time in the laser at the assumed set of parameters.

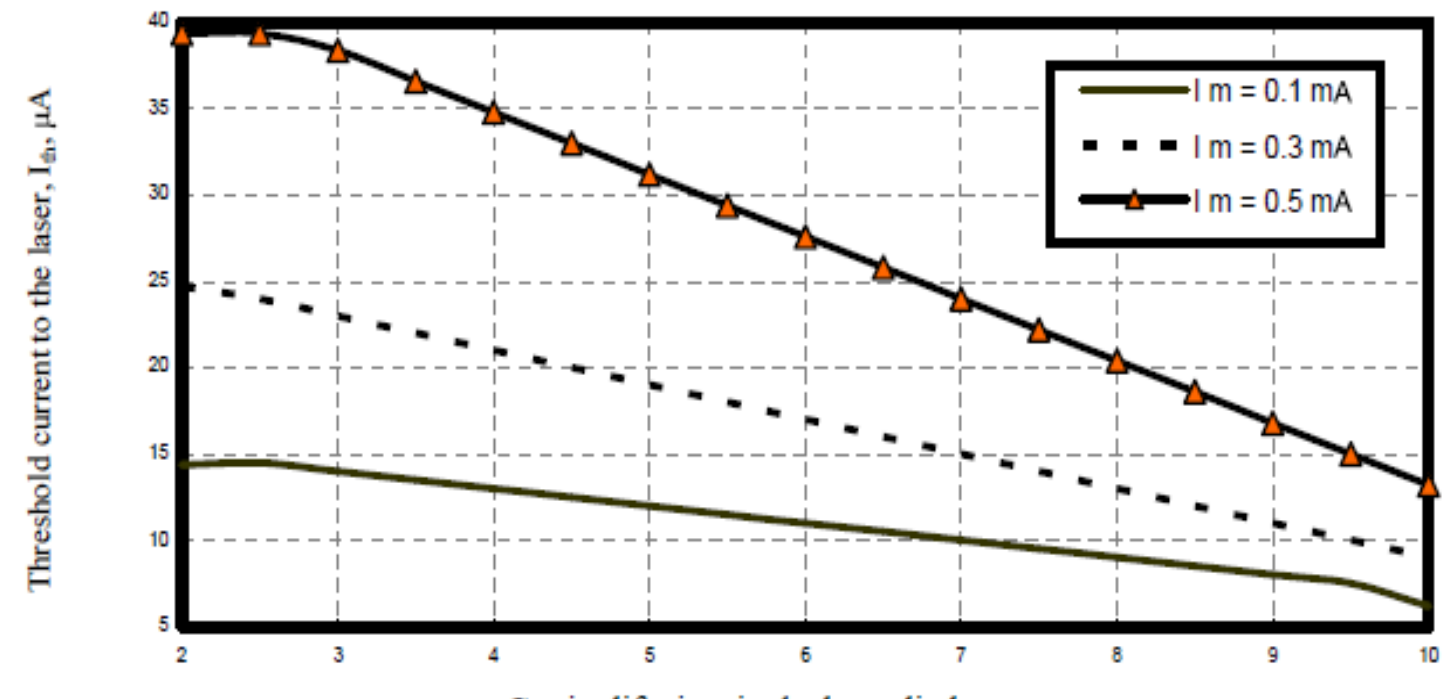

Carrier life time in the laser diode, $\tau$, nsec

Fig. 7. Variations of threshold current to the laser against carrier life time in the laser at the assumed set of parameters. 


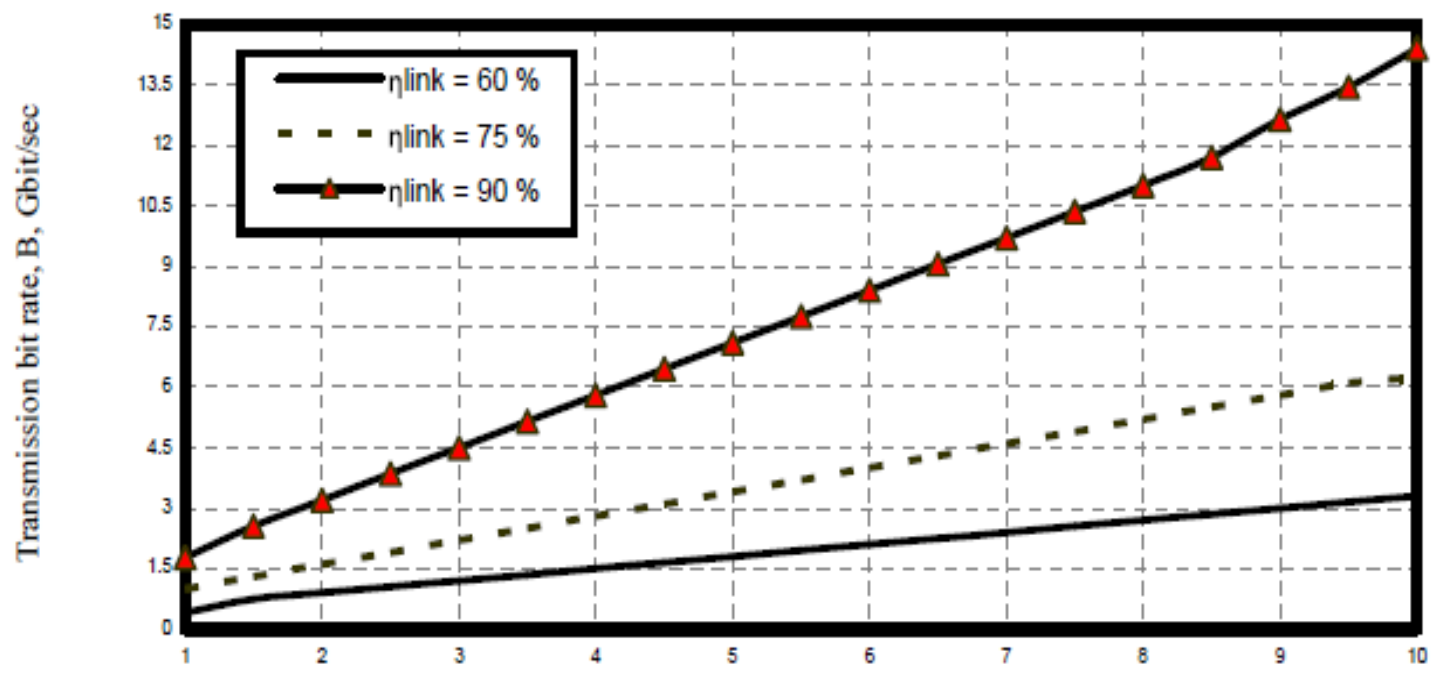

Turn on time of the laser, $\mathrm{t}_{\text {on }}, \mathrm{msec}$

Fig. 8. Variations of transmission bit rate against turn on time of the laser at the assumed set of parameters.

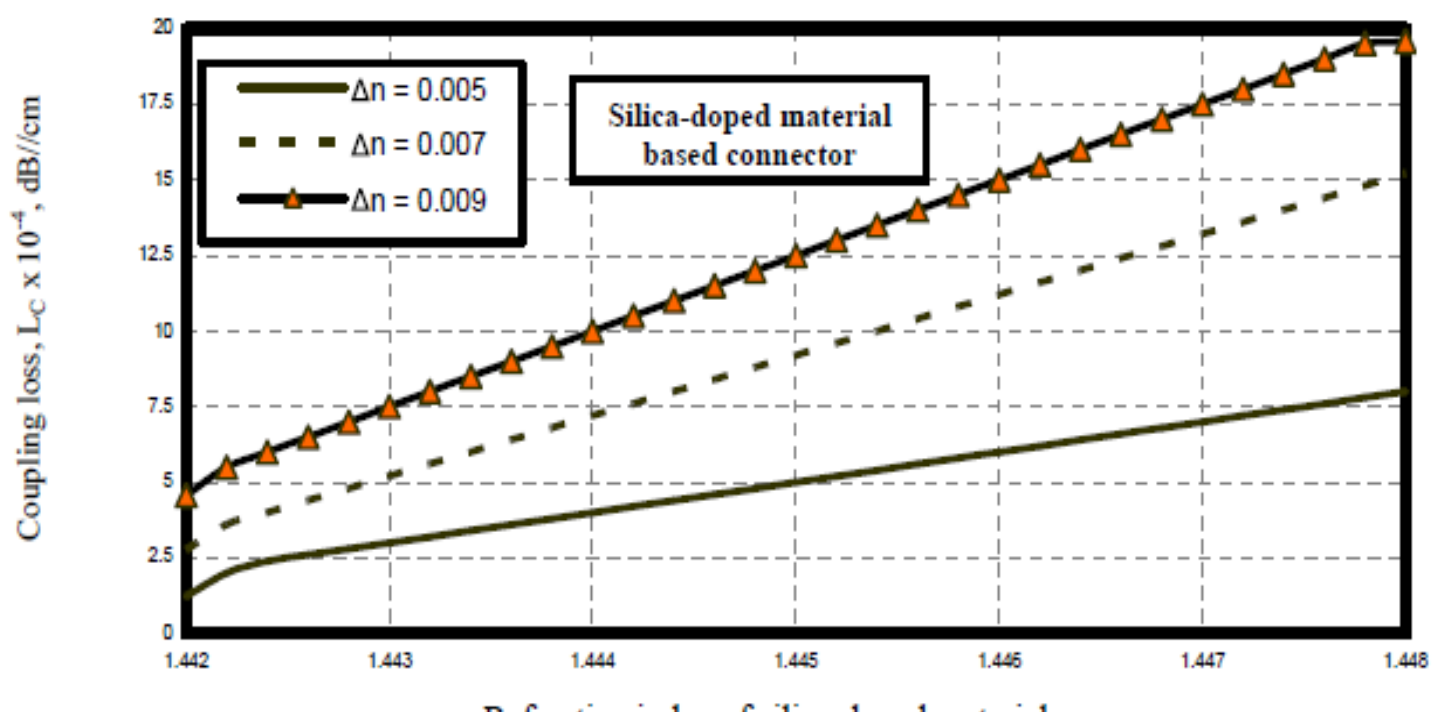

Refractive index of silica-doped material, $n$

Fig. 9. Variations of coupling loss against refractive index of silica-doped material at the assumed set of parameters.

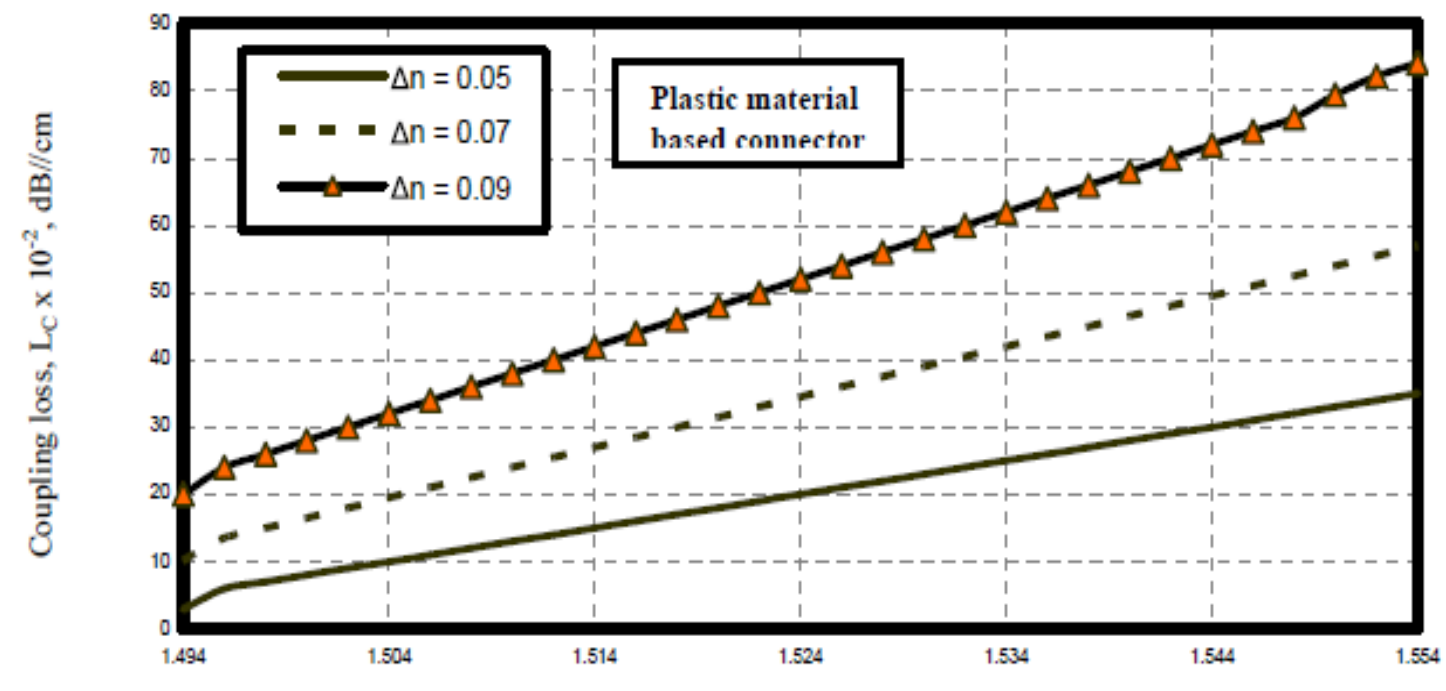

Refractive index of plastic material, $n$

Fig. 10. Variations of coupling loss against refractive index of plastic material at the assumed set of parameters. 


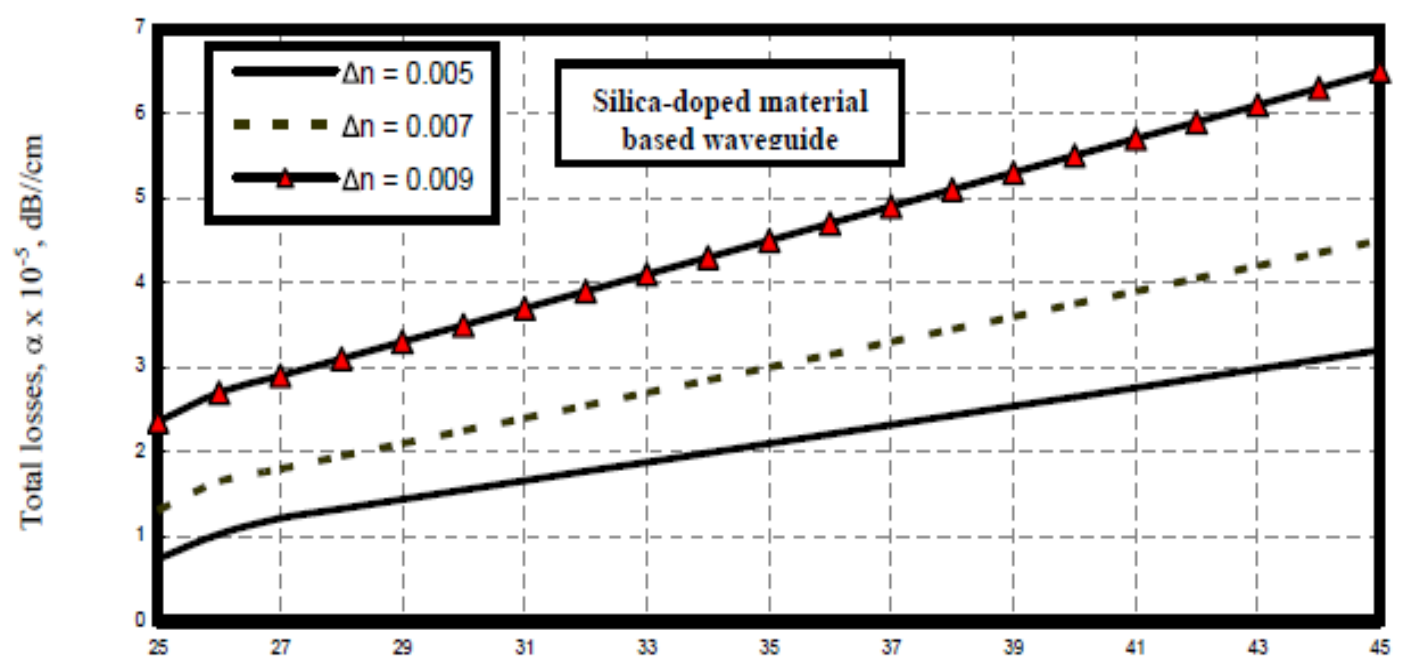

Ambient temperature, $\mathrm{T}, ? \mathrm{C}$

Fig. 11. Variations of total losses against ambient temperature of silica-doped material at the assumed set of parameters.

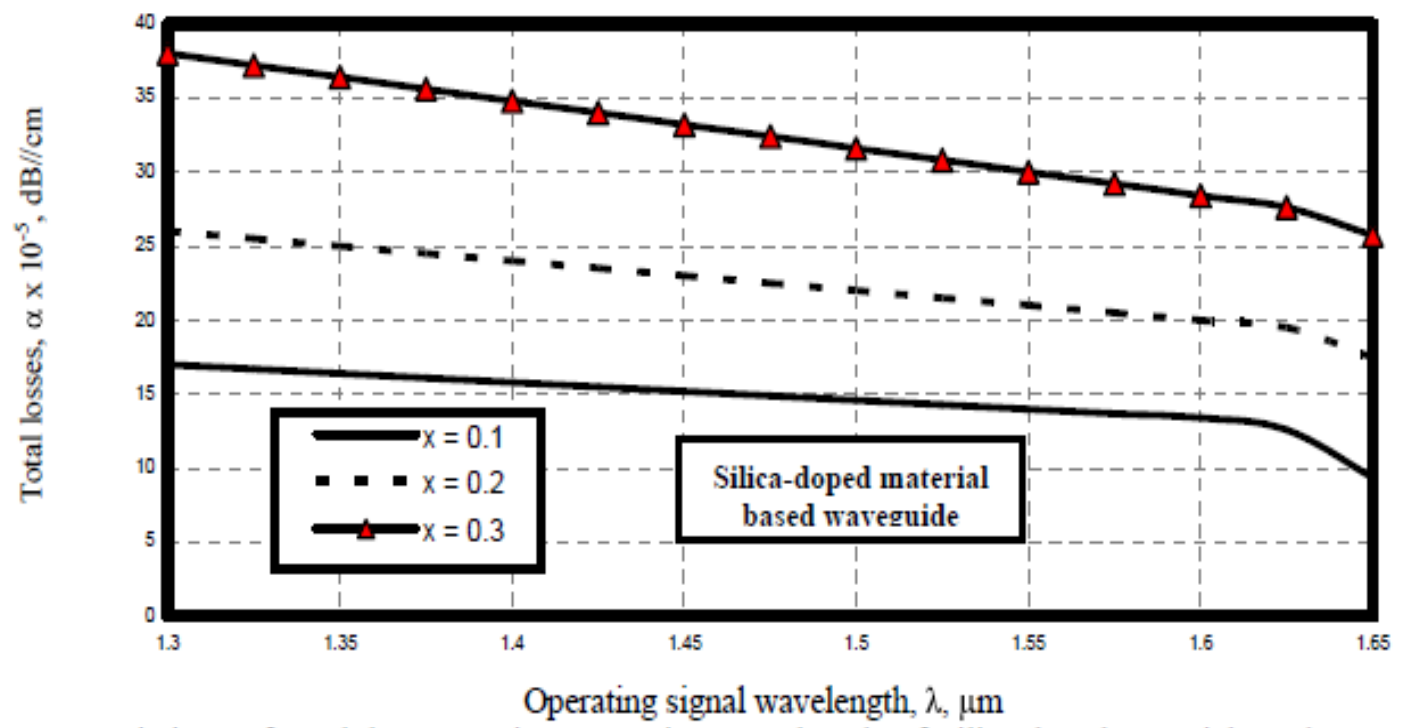

Fig. 12. Variations of total losses against operating wavelength of silica-doped material at the assumed set of parameters.

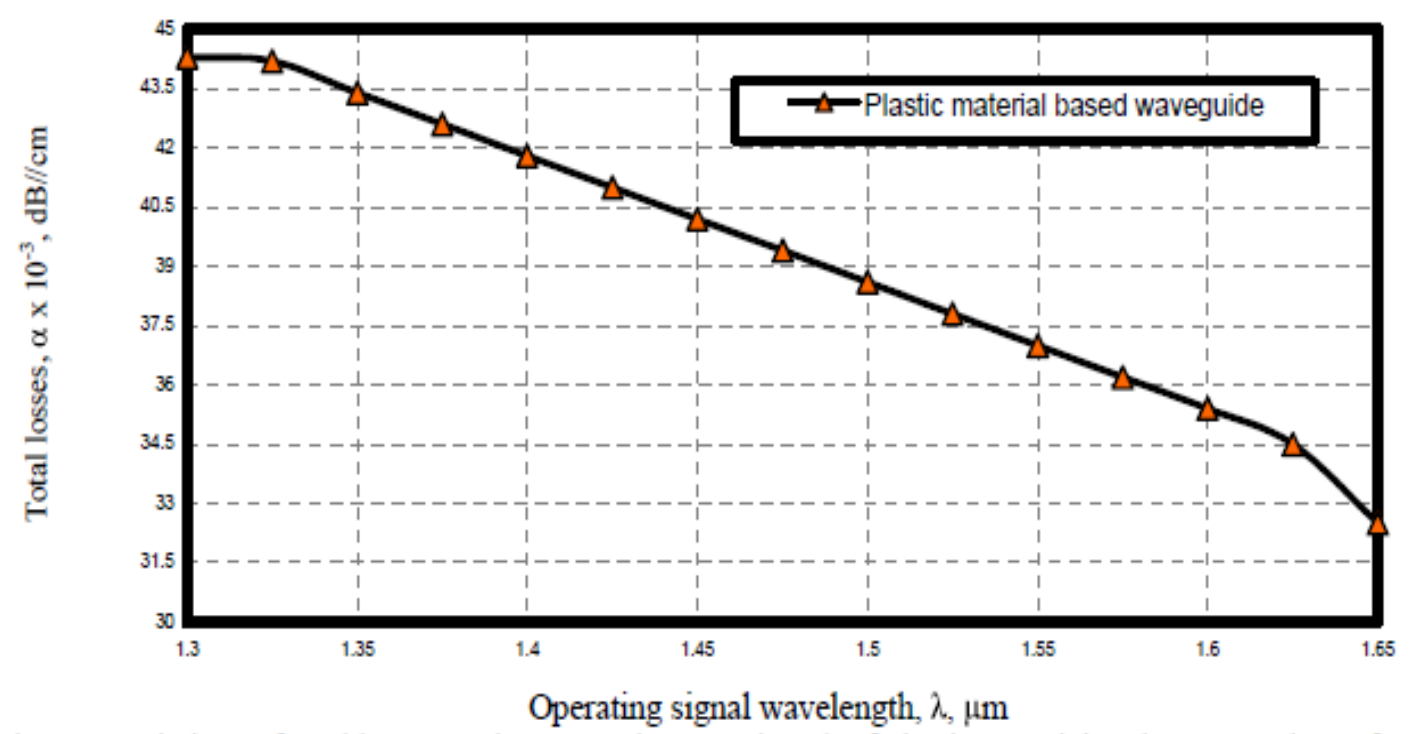

Fig. 13. Variations of total losses against operating wavelength of plastic material at the assumed set of parameters. 


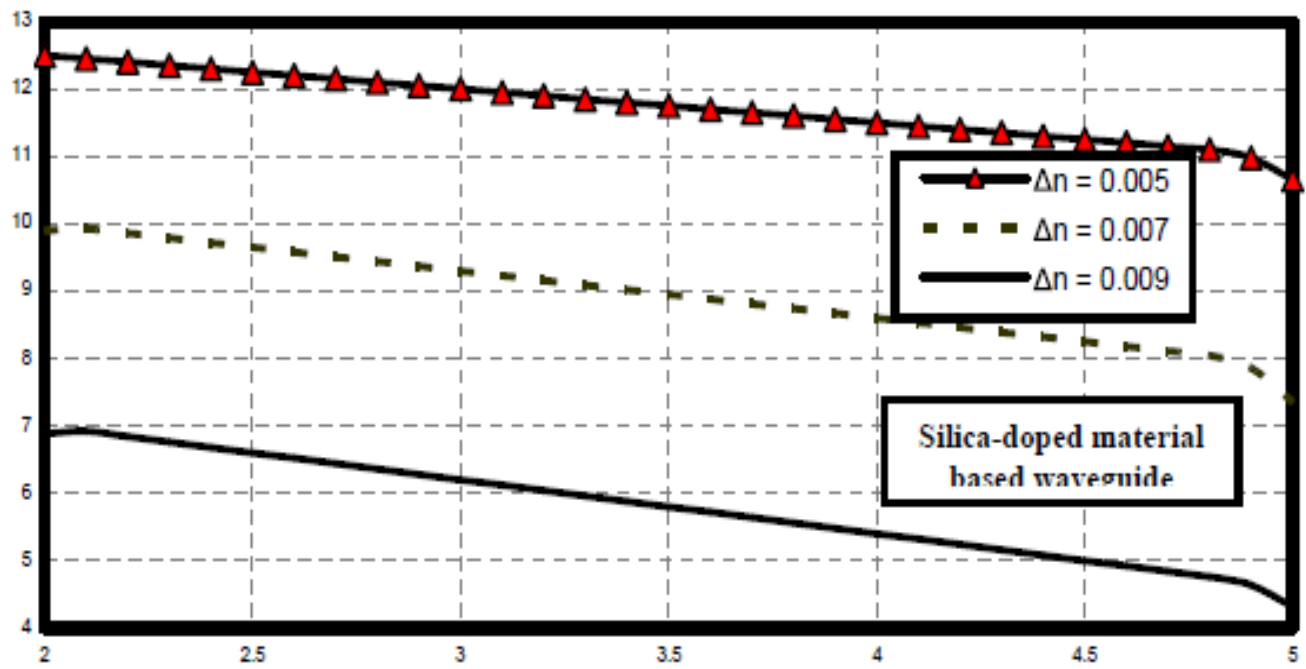

Waveguide length, $\mathrm{L}_{\mathrm{w}}, \mathrm{cm}$

Fig. 14. Variations of classical transmission bit rate versus waveguide length at the assumed set of parameters.

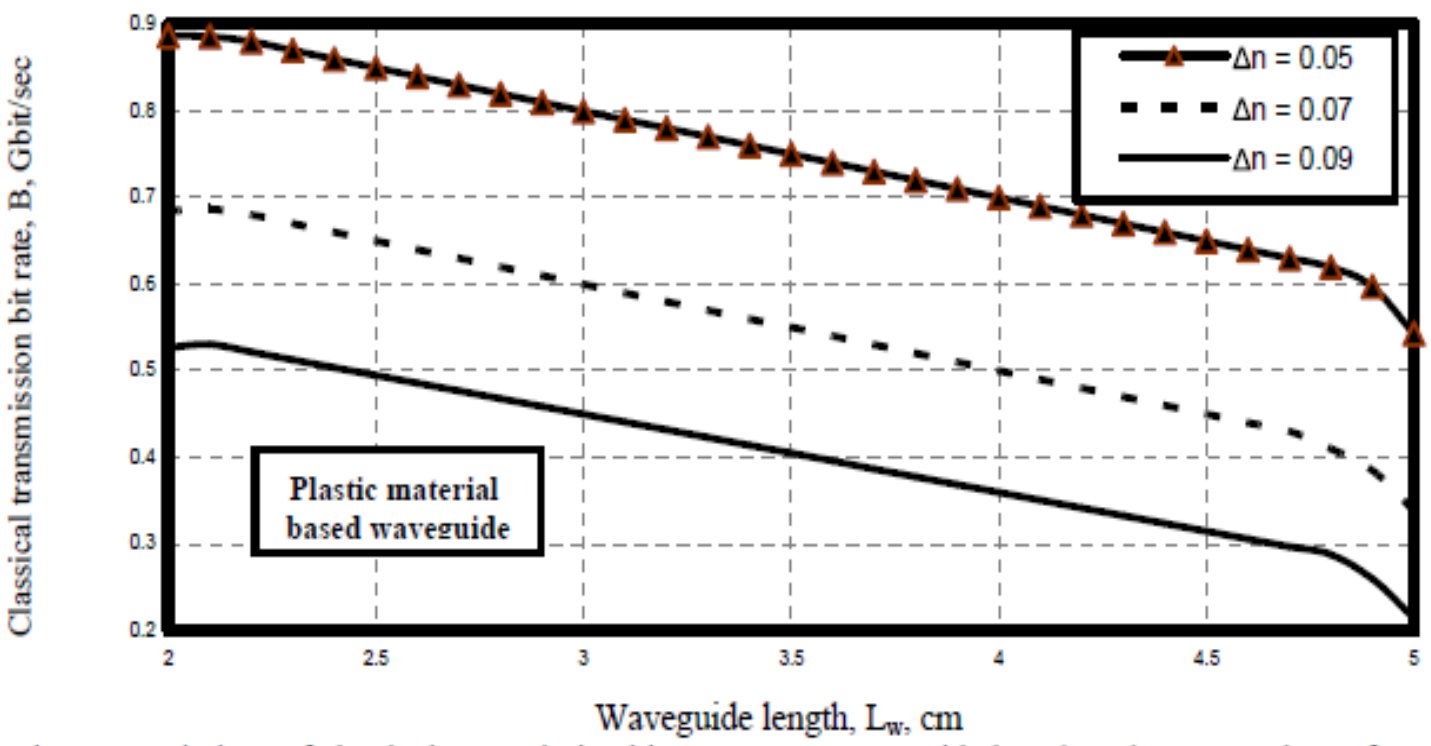

Fig. 15. Variations of classical transmission bit rate versus waveguide length at the assumed set of parameters.

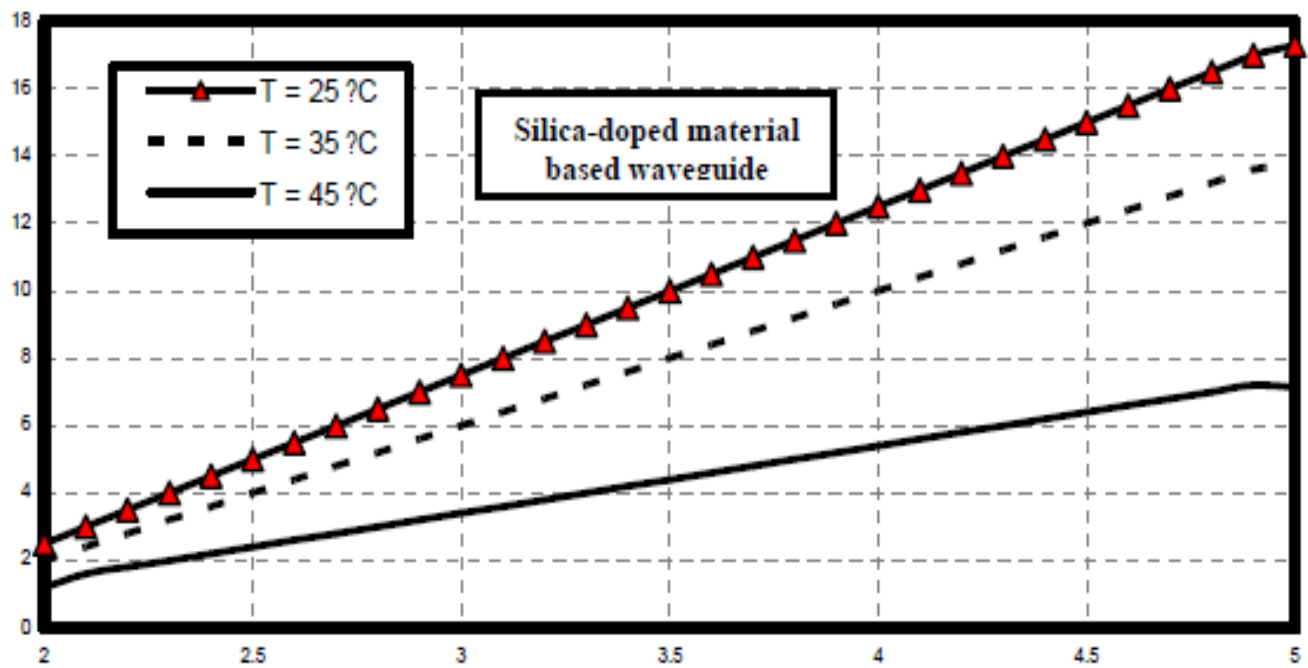

Waveguide length, $\mathrm{L}_{\mathrm{w}}, \mathrm{cm}$

Fig. 16. Variations of bit rate length product versus waveguide length at the assumed set of parameters. 


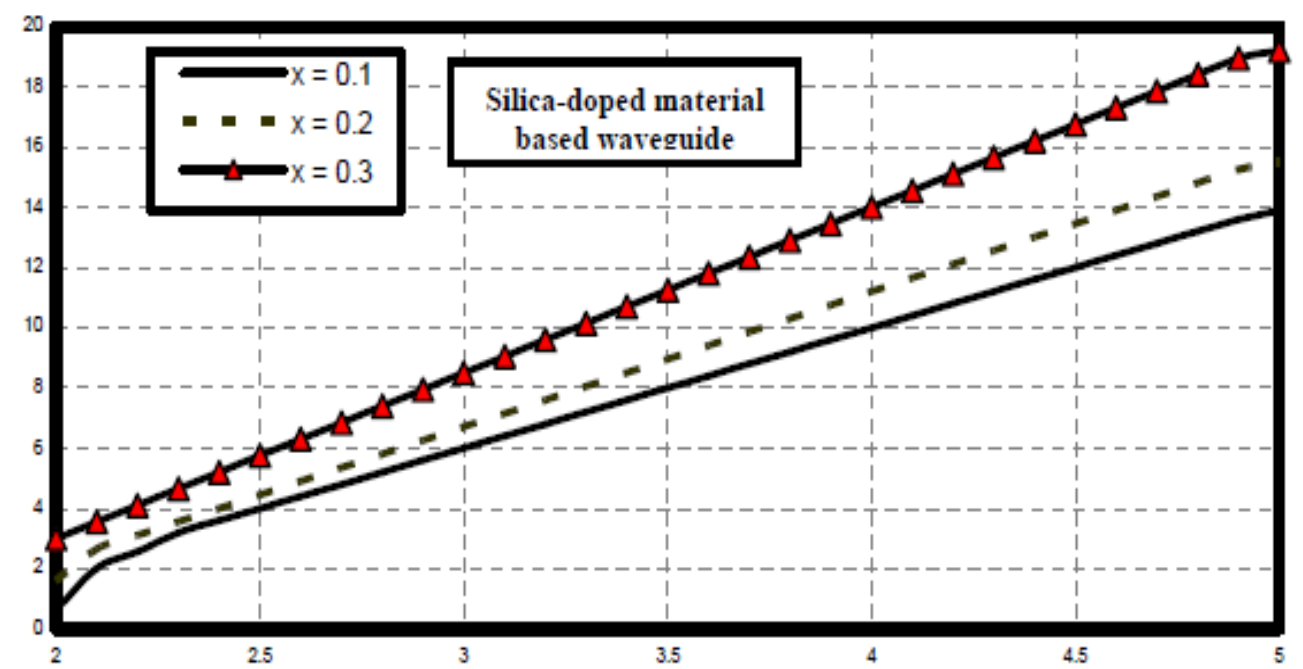

Waveguide length, $\mathrm{L}_{\mathrm{w}}, \mathrm{cm}$

Fig. 17. Variations of bit rate length product versus waveguide length at the assumed set of parameters.

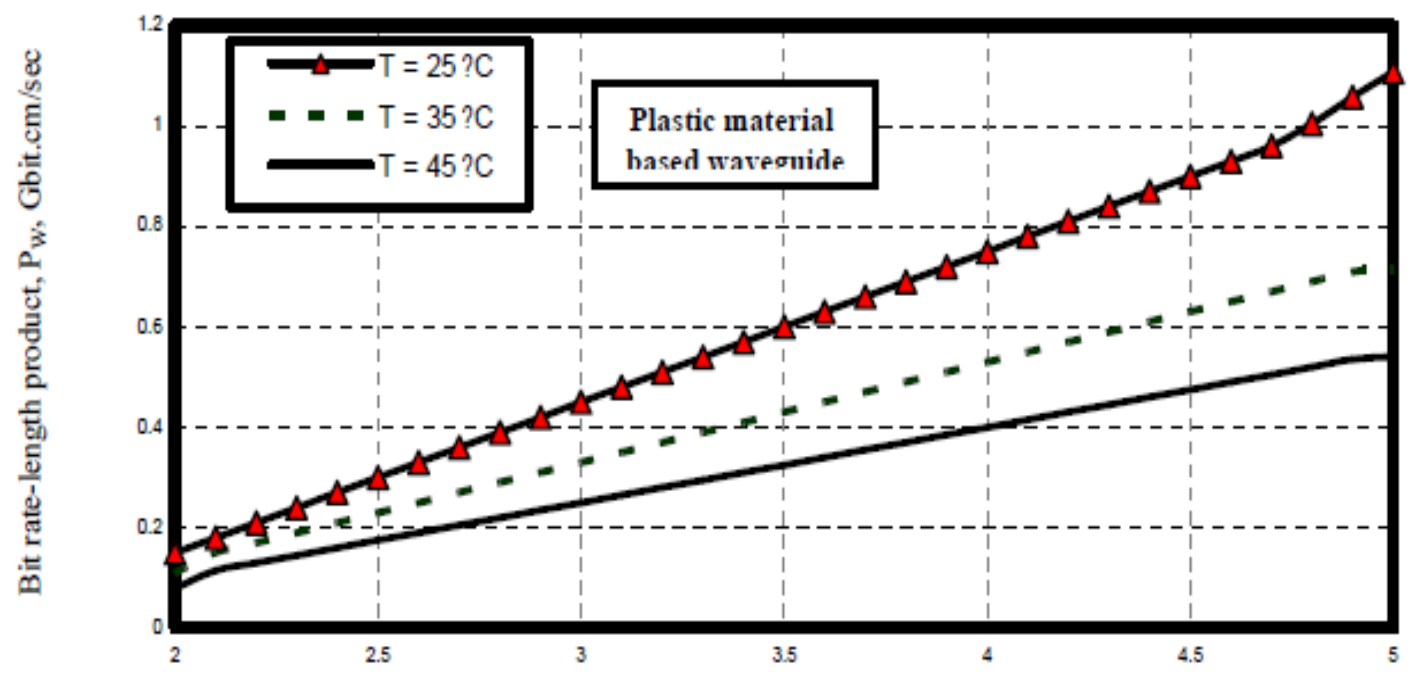

Waveguide length, $\mathrm{L}_{\mathrm{w}}, \mathrm{cm}$

Fig. 18. Variations of bit rate length product versus waveguide length at the assumed set of parameters.

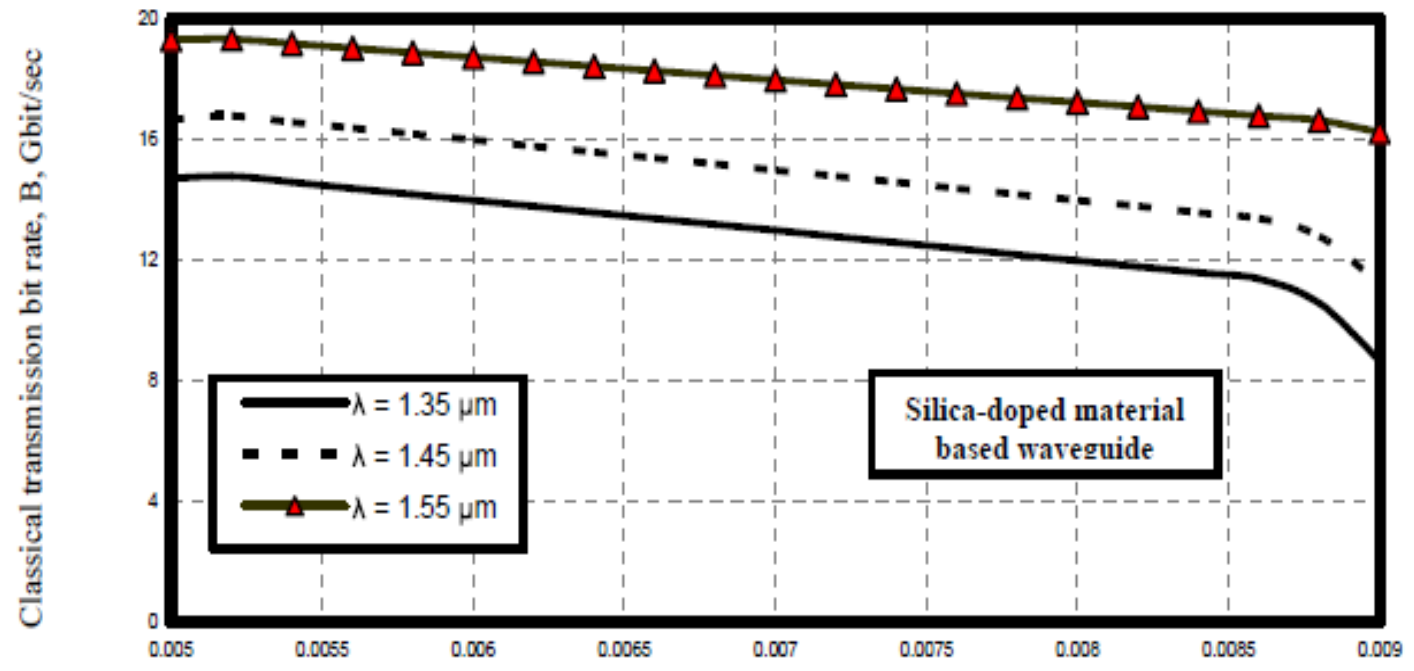

Relative refractive index difference, $\Delta \mathrm{n}$

Fig. 19. Variations of classical transmission versus relative refractive index difference at the assumed set of parameters. 


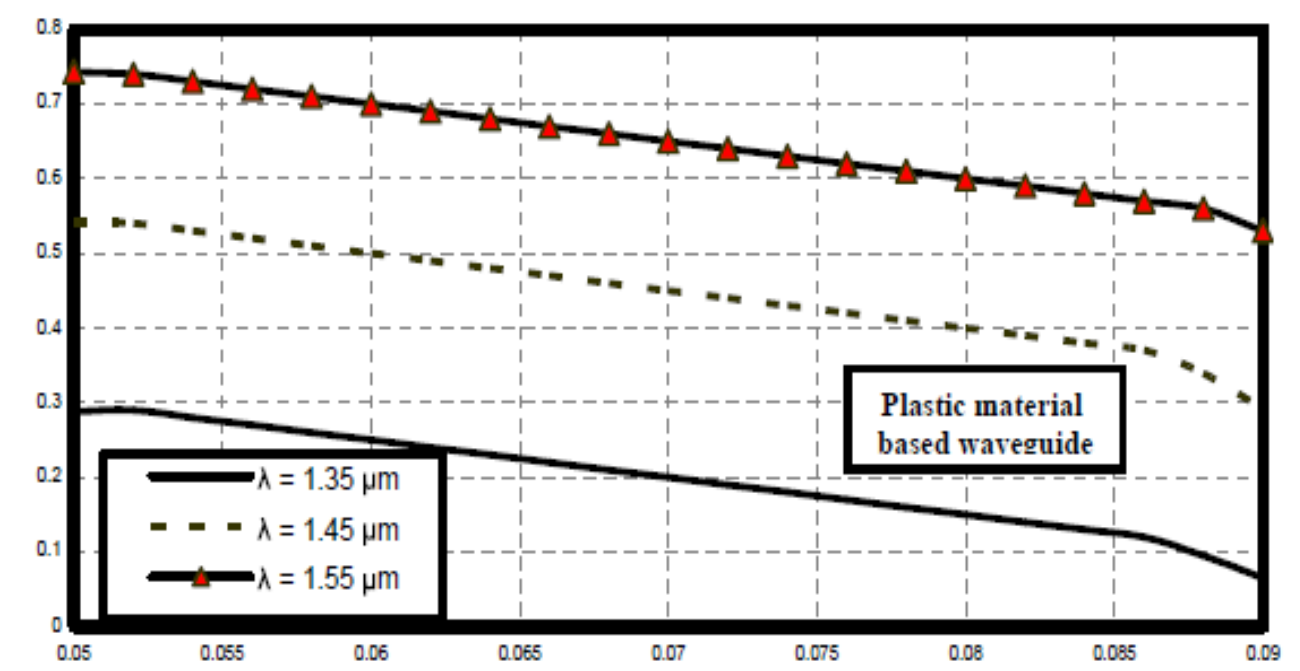

Relative refractive index difference, $\Delta \mathrm{n}$

Fig. 20. Variations of classical transmission versus relative refractive index difference at the assumed set of parameters.

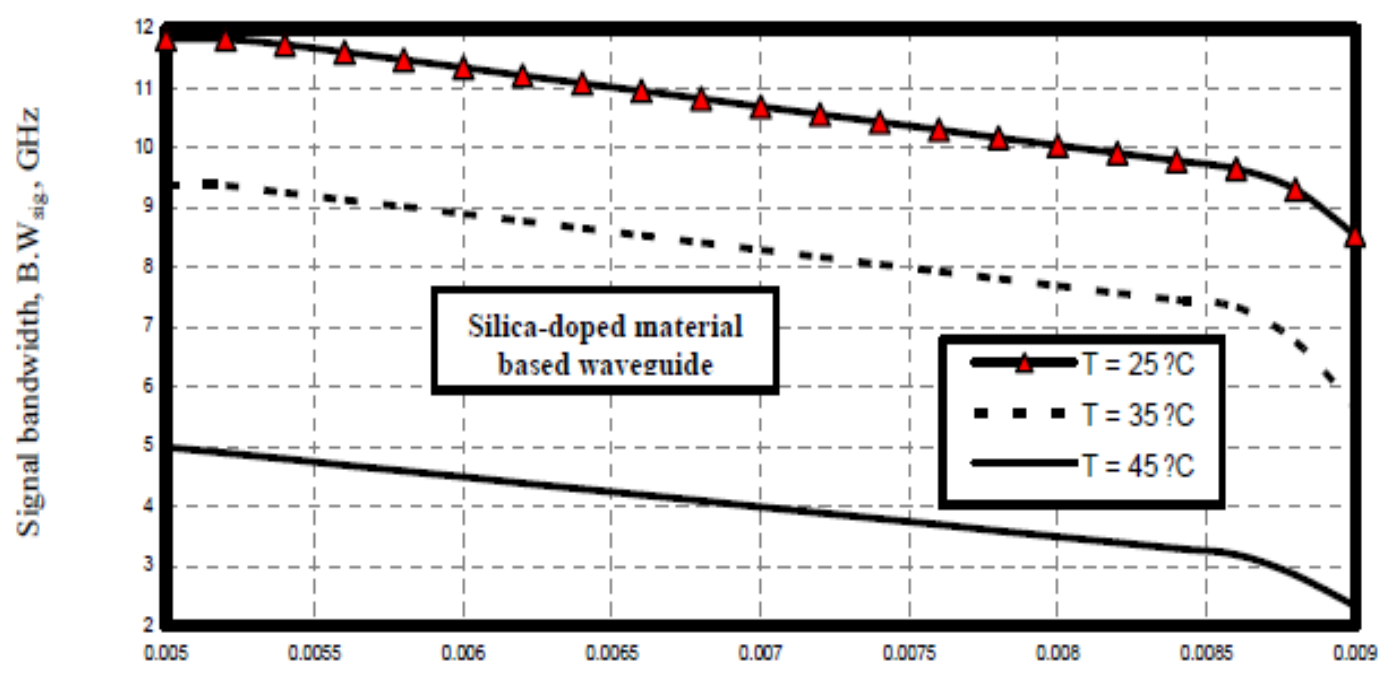

Relative refractive index difference, $\Delta \mathrm{n}$

Fig. 21. Variations of signal bandwidth versus relative refractive index difference at the assumed set of parameters

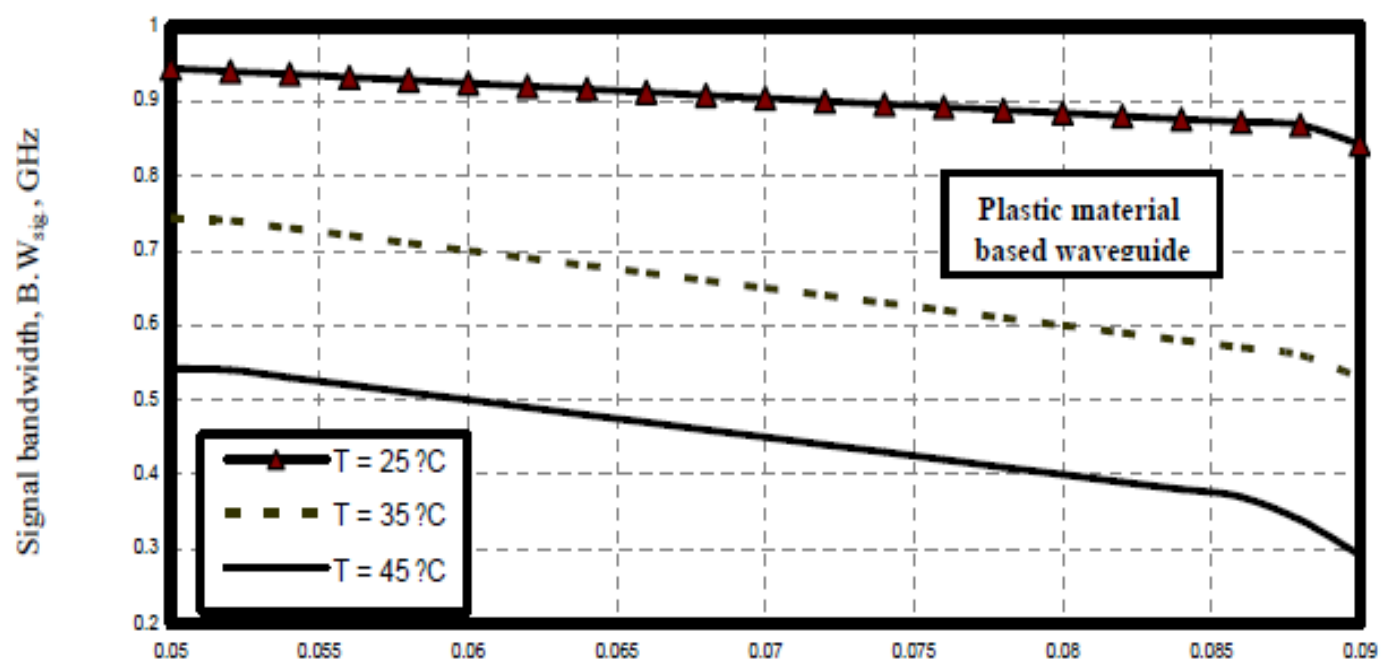

Relative refractive index difference, $\Delta \mathrm{n}$

Fig. 22. Variations of signal bandwidth versus relative refractive index difference at the assumed set of parameters. 


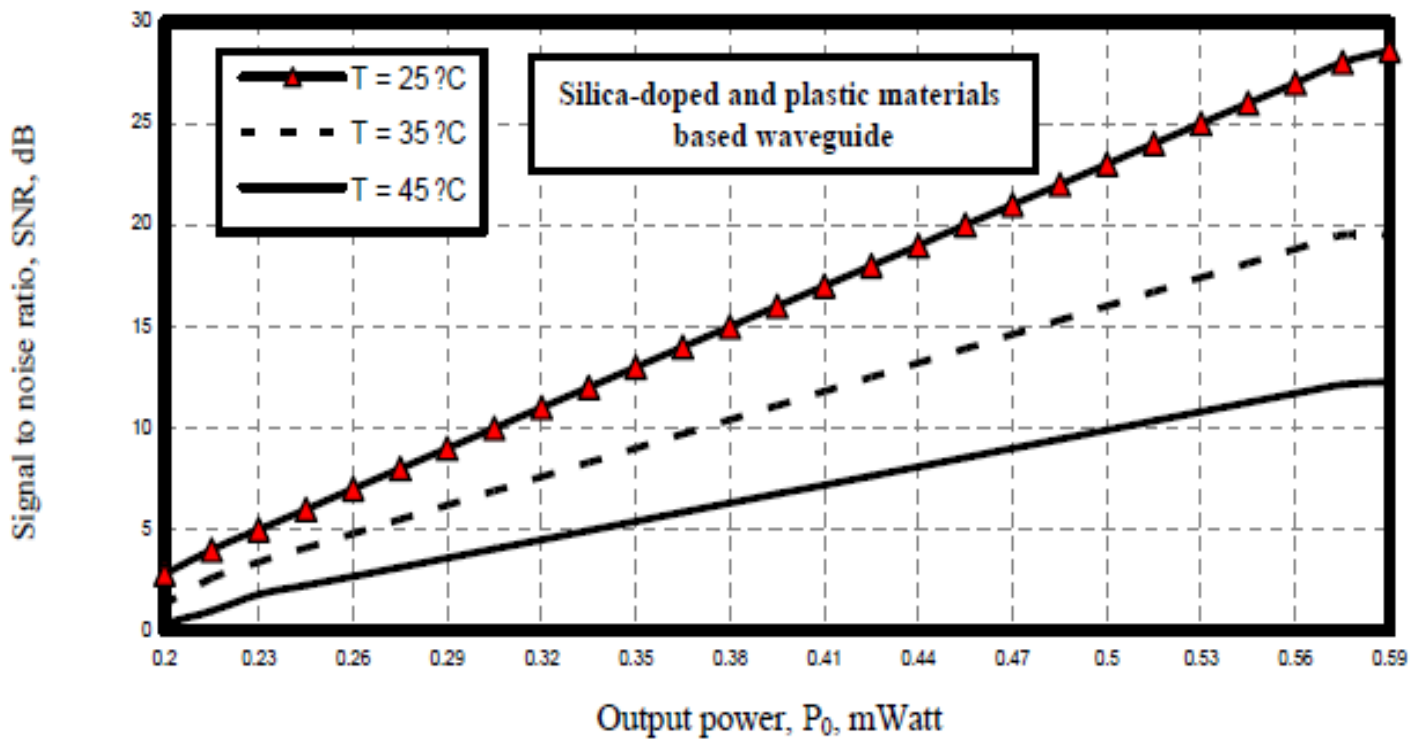

Fig. 23. Variations of signal bandwidth versus relative refractive index difference at the assumed set of parameters.

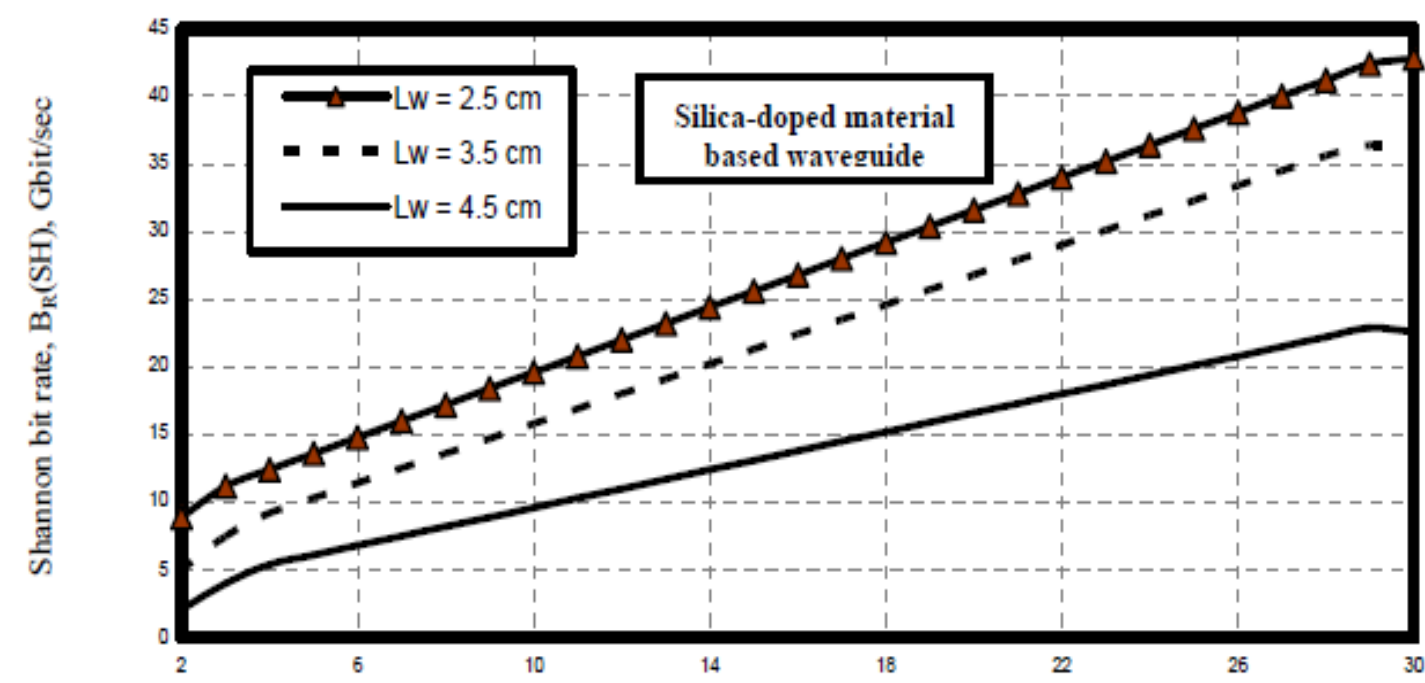

Signal to noise ratio, SNR, dB

Fig. 24. Variations of Shannon transmission bit rate versus signal to noise ratio at the assumed set of parameters.

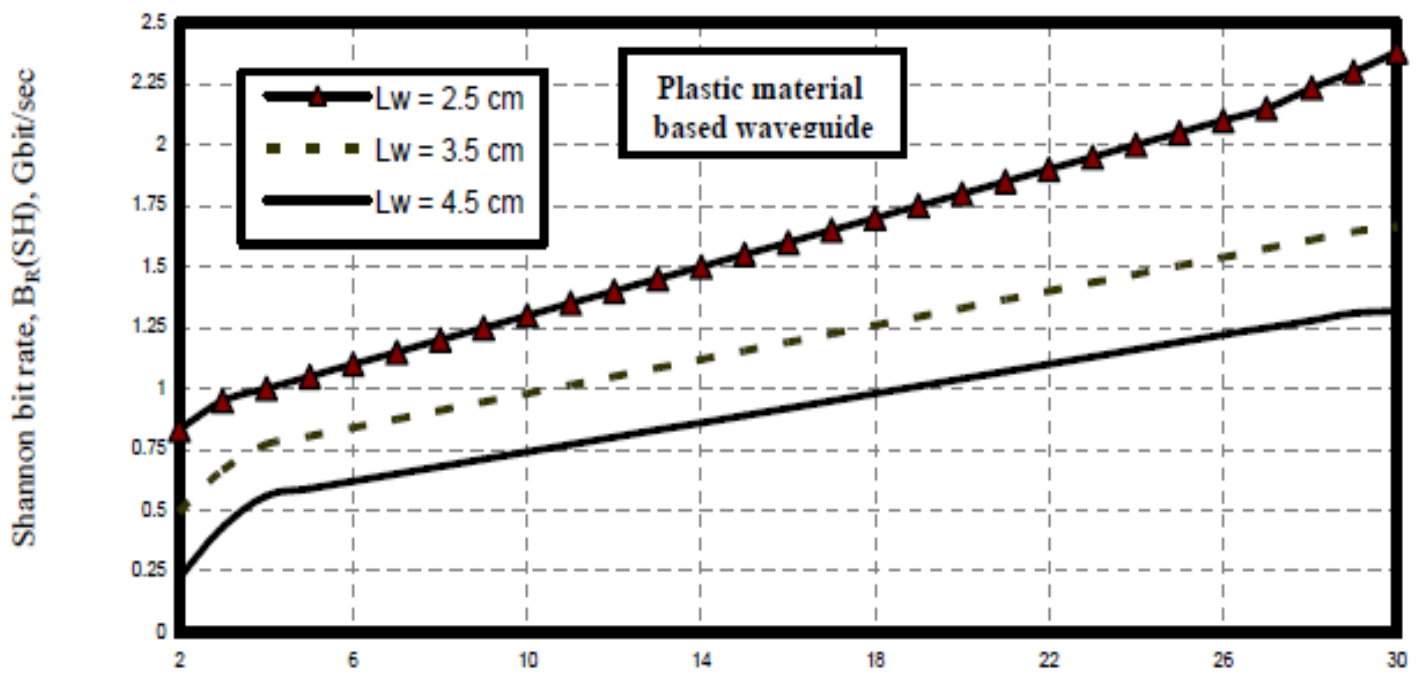

Signal to noise ratio, $\mathrm{SNR}, \mathrm{dB}$

Fig. 25. Variations of Shannon transmission bit rate versus signal to noise ratio at the assumed set of parameters. 


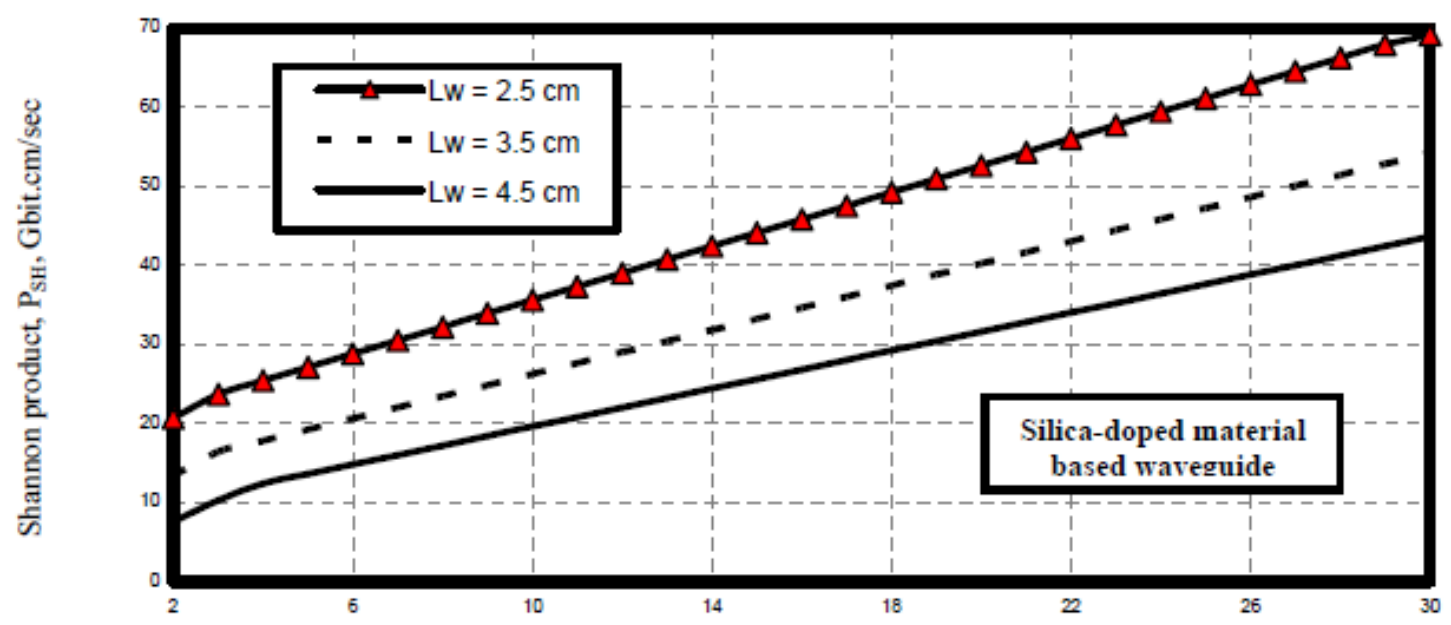

Signal to noise ratio, $\mathrm{SNR}, \mathrm{dB}$

Fig. 26. Variations of Shannon transmission bit rate versus signal to noise ratio at the assumed set of parameters.

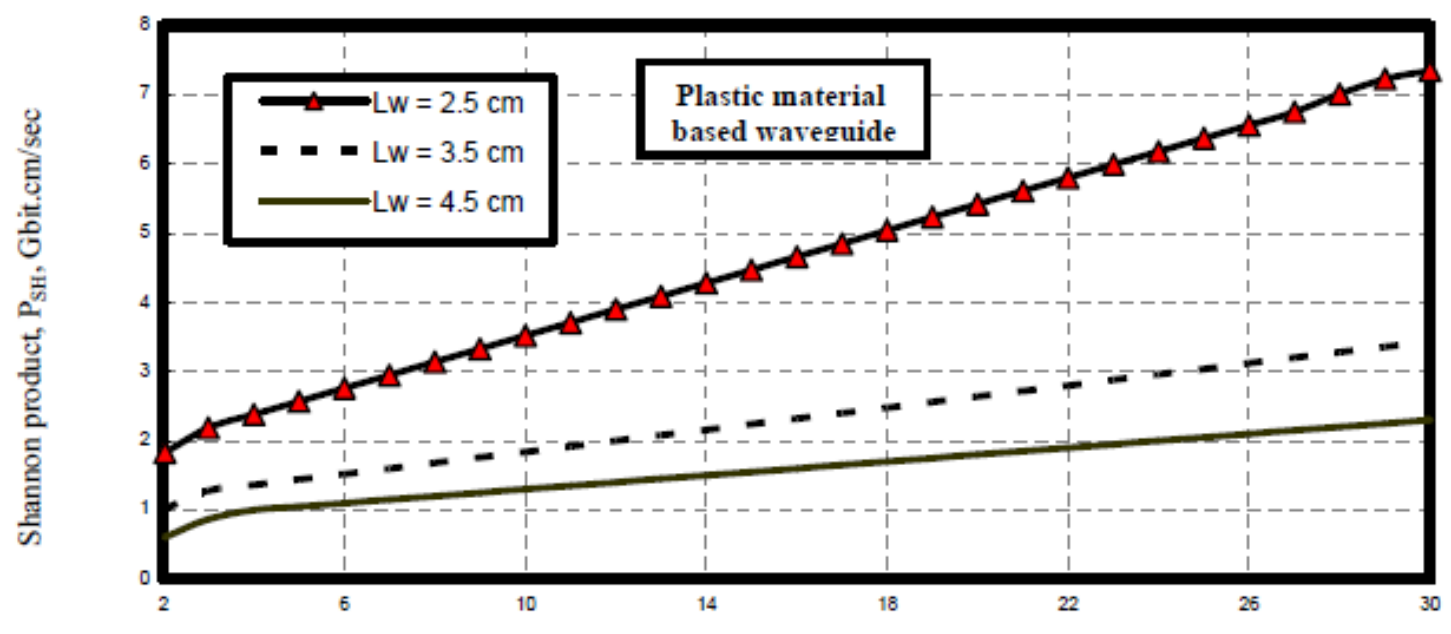

Signal to noise ratio, $\mathrm{SNR}, \mathrm{dB}$

Fig. 27. Variations of Shannon transmission bit rate versus signal to noise ratio at the assumed set of parameters.

\section{Conclusions}

In a summary, we can conclude that the increased drive current to the laser, and turn on voltage of the laser, this leads increase of electrical power that limits the bit error rate. Also the increased carrier life time this leads to increase of transmission bit rate and coupling efficiency to the optical link. The decreased of both relative refractive index difference, and refractive index of silica-doped and plastic materials based connector, this leads to decrease coupling losses. The decreased of both ambient temperature, and percentage amount of germanium added to silica, and the increased operating signal wavelength, this leads to decrease of waveguide loss of silica-doped waveguide. As well as increase operating signal wavelength, this leads to decrease of optical loss of plastic material based waveguide. With decreasing of both ambient temperature, and relative refractive index difference and increasing of both signal to noise ratio, and waveguide length of both silica-doped and plastic materials based waveguide this leads to increasing of both classical bit rate-length and Shannon product for both materials based waveguide. It is evident that silica-doped material based both connector and waveguide present lower optical losses, and higher of both classical transmission bit rate, and product and Shannon transmission bit rate and product than plastic material based of both connector and waveguide.

\section{References}

[1] S. Sygletos, I. Tomkos, and J. Leuthold, "Technological Challenges on the Road Toward Transparent Networking," J. Opt. Network, Vol. 7, No. 2, pp. 321-350, 2008.

[2] D. Fishman, D. L. Correa, E. H. Goode, T. L. Downs, A. Y. Ho, A. Hale, P. Hofmann, B. Basch, and S. Gringeri, "The Rollout of Optical Networking: Lambda Xtreme National Network Deployment," Bell Technology Journal, Vol. 11, No. 3, pp. 55-63, 2006.

[3] S. J. B. Yoo, "Optical Packet and Burst Switching Technologies for the Future Photonic Internet," J. 
Lightwave Technol. Vol. 24, No. 1, pp. 44684492, 2006.

[4] C. W. Chow, G. Talli, A. D. Ellis, and P. D. Townsend, "Rayleigh Noise Mitigation in DWDM LR-PONs Using Carrier Suppressed Subcarrier Amplitude Modulated Phase Shift Keying," Opt. Express Vol. 16, No. 4, pp. 18601866, 2008.

[5] Y. Ishii, S. Koike, Y. Arai, and Y. Ando, "SMT Compatible Large Tolerance Opto Bump Interface for Inter Chip Optical Interconnections," IEEE Trans. Adv. Packag., Vol. 26, No. 2, pp. 122-127, May 2003.

[6] Y. Ishii, N. Tanaka, T. Sakamoto, and H. Takahara, "Fully SMT Compatible Optical I/O Package With Microlens Array Interface," J. Lightw. Technol., Vol. 21, No. 1, pp. 275-280, Jan. 2003.

[7] J. A. Kash, "Internal Optical Interconnects in Next Generation High Performance Servers," IEEE Fiber Optics Photon., Vol. 3, No. 1, pp. 29-30, Sep. 2005.

[8] S. H. Hwang, M. H. Cho, S.-K. Kang, H.-H. Park, S.-H. Kim, K.-U. Shin, and S.-W. Ha, "Passively Assembled Optical Interconnection System Based on an Optical Printed Circuit Board," IEEE Photon. Technol. Lett., Vol. 18, No. 3, pp. 652654, Mar. 2006.

[9] S. H. Hwang, M. H. Cho, S.-K. Kang, T.-W. Lee, and H.-H. Park, "Two Dimensional Optical Interconnection Based on 2-Layered Optical Printed Circuit Board," IEEE Photon. Technol. Lett., Vol. 19, No. 5, pp. 411-413, Mar. 2007.

[10] T. R. Chen, L. E. Eng, B. Zhao, Y. H. Zhuang, and A. Yariv, "Strained Single Quantum Well InGaAs Lasers With A threshold Current of 0.25 mA," Appl. Physics Letters., Vol. 63, No. 19, pp. 2621-2623, 1993.

[11] T. Odagawa, K. Nakajima, K. Tanaka, H. Nobuhara, T. Inoue, N. Okazaki, and K. Wakao, "High Speed Operation of Strained InGaAs/InGaAsP MQW Lasers Under Zero Bias Condition," IEEE J. Quantum Electronics, Vol. 29, No. 6, pp. 1282-1286, 1993.

[12] David K. Cheng, Field and Wave Electromagnetics ( $2^{\text {nd }}$ edition), Prentice Hall, 1989.

[13] B. Saleh and M. C. Teich, Fundamental of photonics, Wiley-Inters cience, 1991.

[14] W. Fleming, "Dispersion in $\mathrm{GeO}_{2}-\mathrm{SiO}_{2}$ Glasses," Applied Optics, Vol. 23, No. 24, pp. 4486-4493, 1984.

[15] T. Ishigure, E. Nihei, and Y. Koike, "Optimum Refractive Index Profile of the Graded-Index
Polymer Optical Fiber, Toward Gigabit Data Links," Appl. Opt., Vol. 35, No.12, pp. 20482053, 1996.

[16] Abd El-Naser A. Mohammed, Gaber E. S. M. ElAbyad, Abd El-Fattah A. Saad, and Ahmed Nabih Zaki Rashed, "High Transmission Bit Rate of A thermal Arrayed Waveguide Grating (AWG) Module in Passive Optical Networks," IJCSIS International Journal of Computer Science and Information Security, Vol. 1, No. 1, pp. 13-22, May 2009.

[17] I. P. Kaminow and T. L. Koch, Optical Fiber Telecommunications, III, New York: Academic Press, 1997.

[18] A. Pilipetskii, "High Transmission Capacity Undersea Long Haul Communication Systems," J. Lightwave Technol., Vol. 12, No. 4, pp. 484-496, 2006.

[19] Abd El-Naser A. Mohammed, Abd El-Fattah A. Saad, and Ahmed Nabih Zaki Rashed and Mahomud M. Eid, "Characteristics of MultiPumped Raman Amplifiers in Dense Wavelength Division Multiplexing (DWDM) Optical Access Networks," IJCSNS International Journal of Computer Science and Network Security, Vol. 9, No. 2, pp. 277-284, Feb. 2009.

[20] Abd El-Naser A. Mohammed, and Ahmed Nabih Zaki Rashed, "Comparison Performance Evolution of Different Transmission Techniques With Bi-directional Distributed Raman Gain Amplification Technique in High Capacity Optical Networks," International Journal of Physical Sciences, Vol. 5, No. 5, pp. 484-495, May 2010.

\section{Author's Profile}

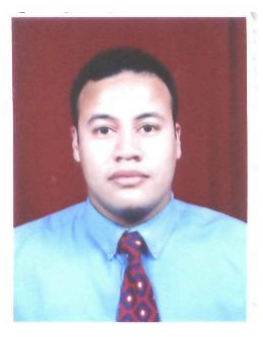

Dr. Ahmed Nabih Zaki Rashed was born in Menouf city, Menoufia State, Egypt country in 23 July, 1976. Received the B.Sc., M.Sc., and Ph.D. scientific degrees in the Electronics and Electrical Communications Engineering Department from Faculty of Electronic Engineering, Menoufia University in 1999, 2005, and 2010 respectively. Currently, his job carrier is a scientific lecturer in Electronics and Electrical Communications Engineering Department, Faculty of Electronic Engineering, Menoufia university, Menouf. Postal Menouf city code: 32951, EGYPT.

His scientific master science thesis has focused on polymer fibers in optical access communication systems. Moreover his scientific Ph. D. thesis has focused on recent applications in linear or nonlinear passive or active in optical networks. His interesting 
research mainly focuses on transmission capacity, a data rate product and long transmission distances of passive and active optical communication networks, wireless communication, radio over fiber communication systems, and optical network security and management. He has published many high scientific research papers in high quality and technical international journals in the field of advanced communication systems, optoelectronic devices, and passive optical access communication networks. His areas of interest and experience in optical communication systems, advanced optical communication networks, wireless optical access networks, analog communication systems, optical filters and Sensors, digital communication systems, optoelectronics devices, and advanced material science, network management systems, multimedia data base, network security, encryption and optical access computing systems. As well as he is editorial board member in high academic scientific International research Journals. Moreover he is a reviewer member and editorial board member in high impact scientific research international journals in the field of electronics, electrical communication systems, optoelectronics, information technology and advanced optical communication systems and networks. His personal electronic mail: ahmed_733@yahoo.com

How to cite this paper: Ahmed Nabih Zaki Rashed,"Current Trends of High capacity Optical Interconnection Data Link in High Performance Optical Communication Systems", International Journal of Intelligent Systems and Applications(IJISA), vol.5, no.3, pp.94-110, 2013.DOI: 10.5815/ijisa.2013.03.10 